\title{
Controls on terrestrial carbon feedbacks by productivity versus turnover in the CMIP5 Earth System Models
}

\author{
C. D. Koven ${ }^{1}$, J. Q. Chambers ${ }^{1}$, K. Georgiou ${ }^{1}$, R. Knox ${ }^{1}$, R. Negron-Juarez ${ }^{1}$, W. J. Riley ${ }^{1}$, V. K. Arora ${ }^{2}$, V. Brovkin ${ }^{3}$, \\ P. Friedlingstein ${ }^{4}$, and C. D. Jones ${ }^{5}$ \\ ${ }^{1}$ Earth Sciences Division, Lawrence Berkeley National Laboratory, Berkeley, California, USA \\ ${ }^{2}$ Canadian Centre for Climate Modelling and Analysis, Victoria, Canada \\ ${ }^{3}$ Max Planck Institute for Meteorology, Hamburg, Germany \\ ${ }^{4}$ College of Engineering, Mathematics and Physical Sciences, University of Exeter, Exeter, UK \\ ${ }^{5}$ Met Office Hadley Centre, Exeter, UK \\ Correspondence to: C. D. Koven (cdkoven@lbl.gov)
}

Received: 24 March 2015 - Published in Biogeosciences Discuss.: 16 April 2015

Revised: 7 August 2015 - Accepted: 25 August 2015 - Published: 7 September 2015

\begin{abstract}
To better understand sources of uncertainty in projections of terrestrial carbon cycle feedbacks, we present an approach to separate the controls on modeled carbon changes. We separate carbon changes into four categories using a linearized, equilibrium approach: those arising from changed inputs (productivity-driven changes), and outputs (turnover-driven changes), of both the live and dead carbon pools. Using Coupled Model Intercomparison Project Phase 5 (CMIP5) simulations for five models, we find that changes to the live pools are primarily explained by productivitydriven changes, with only one model showing large compensating changes to live carbon turnover times. For dead carbon pools, the situation is more complex as all models predict a large reduction in turnover times in response to increases in productivity. This response arises from the common representation of a broad spectrum of decomposition turnover times via a multi-pool approach, in which flux-weighted turnover times are faster than mass-weighted turnover times. This leads to a shift in the distribution of carbon among dead pools in response to changes in inputs, and therefore a transient but long-lived reduction in turnover times. Since this behavior, a reduction in inferred turnover times resulting from an increase in inputs, is superficially similar to priming processes, but occurring without the mechanisms responsible for priming, we call the phenomenon "false priming", and show that it masks much of the intrinsic changes to dead carbon turnover times as a result of changing climate. These patterns hold across the fully coupled, biogeochem-
\end{abstract}

ically coupled, and radiatively coupled $1 \% \mathrm{yr}^{-1}$ increasing $\mathrm{CO}_{2}$ experiments. We disaggregate inter-model uncertainty in the globally integrated equilibrium carbon responses to initial turnover times, initial productivity, fractional changes in turnover, and fractional changes in productivity. For both the live and dead carbon pools, inter-model spread in carbon changes arising from initial conditions is dominated by model disagreement on turnover times, whereas inter-model spread in carbon changes from fractional changes to these terms is dominated by model disagreement on changes to productivity in response to both warming and $\mathrm{CO}_{2}$ fertilization. However, the lack of changing turnover time control on carbon responses, for both live and dead carbon pools, in response to the imposed forcings may arise from a common lack of process representation behind changing turnover times (e.g., allocation and mortality for live carbon; permafrost, microbial dynamics, and mineral stabilization for dead carbon), rather than a true estimate of the importance of these processes.

\section{Introduction}

Terrestrial carbon cycle feedbacks represent a large and highly uncertain factor governing the response of the global climate system to human greenhouse gas emissions (Gregory et al., 2009). Historically, only about half of anthropogenic carbon dioxide emissions have remained in the atmosphere 
where they act to enhance the greenhouse effect, while the other half has been incorporated into either the ocean or land carbon pools (Ciais et al., 2013). Models of the global carbon cycle have represented this response as being primarily driven by the biogeochemical effects of increasing carbon concentration (known as carbon-concentration feedbacks); however, these models differ greatly on whether such sinks will continue in the future, or whether they will be partially offset by the response of the ocean and land carbon cycles to changing climate (carbon-climate feedbacks). Through successive generations of offline and coupled carbon cycle climate model (hereinafter Earth system model, or ESM) intercomparisons, such uncertainties have remained large, particularly for the case of terrestrial carbon feedbacks (Cramer et al., 2001; Friedlingstein et al., 2006; Sitch et al., 2008; Arora et al., 2013).

The mechanisms underpinning terrestrial carbon cycle feedbacks are complex, because both the $\mathrm{CO}_{2}$ concentrationand climate-driven changes to the atmosphere have multiple effects that propagate throughout terrestrial ecosystems. The primary effect of the carbon-concentration feedback on land is to increase the ability of plants to photosynthesize. This increase in productivity, which is widely observed in natural ecosystems (Norby et al., 2005), leads to multiple ecosystemlevel changes, including changes to nutrient availability and the distributions of carbon among the many ecosystem components (Norby et al., 2010; De Kauwe et al., 2014). ESMs predict that this increase in productivity leads to greater carbon uptake relative to losses and a net transient increase in ecosystem carbon, which has persisted historically as a result of continuously increasing $\mathrm{CO}_{2}$ concentrations. The changes to carbon uptake then propagate to the dead pools, as a continuously increasing net transfer of carbon from live to dead pools leads to a persistent disequilibrium between gain and loss in the dead pools as well.

Climate change itself exerts many complex direct controls on ecosystem carbon storage: climate regulates the ability of plants to photosynthesize, as temperature and hydrological changes may each lead to changes in productivity as a result of climate change. Climate also affects the allocation of newly photosynthesized carbon, the length of the growing season, the changing distributions of plant species, and mortality from disturbances such as drought, fire, and pathogens. Furthermore, climate change is likely to change the direct losses of carbon from ecosystems via changes in plant autotrophic respiration, fire, and heterotrophic respiration that accompanies decomposition of dead pools. As a result, we expect climate change to directly affect both the inputs and outputs of carbon to ecosystems through multiple processes.

The complexity of terrestrial carbon cycle responses to changes in $\mathrm{CO}_{2}$ concentrations and climate makes it difficult to attribute uncertainty in the magnitude of carbon feedbacks to the specific processes that most strongly govern these feedbacks. Recent studies have pointed to climate control on net primary productivity (Fung et al., 2005), soil respi- ration (Jones et al., 2003), tropical forest conversion to savannah (Friedlingstein et al., 2006), and changes to the turnover times of live carbon (Friend et al., 2014) as dominant sources of ESM uncertainty. This diversity of explanations for the governing controls on the magnitude of terrestrial carbon cycle feedbacks makes it difficult to infer what process-level understanding is most urgently required to reduce this uncertainty. Furthermore, there exist entire categories of processes that are not even represented in current ESMs and which may have large and uncertain implications, for example the carbon dynamics in permafrost-affected soils (Koven et al., 2011), the microbial processes underpinning decomposition (Wieder et al., 2014; Riley et al., 2014), or multiple nutrient limitations (Zhang et al., 2013).

The goal of this paper is to understand which aspects of terrestrial carbon cycling most strongly control carbon cycle feedbacks in ESMs. To do this, as a first level of disaggregation, we separate the ESM responses for two sets of pools: the live carbon (composed of vegetation biomass), and the dead carbon (composed of decomposing soil and litter carbon). This distinction is common to all ESM terrestrial carbon cycle components and easily identified in natural ecosystems. We recognize that the naming choice of "live" and "dead" is somewhat simplified, given that in real ecosystems, a large fraction of the biomass is actually dead heartwood tissue and some of the decomposing carbon mass is actually live heterotrophs, but we nonetheless follow this simplified convention here and refer to all vegetation biomass carbon as "live" and all decomposing carbon as "dead". As a second level of disaggregation, we examine the relative roles of changing carbon inputs versus carbon outputs. This approach allows us to define four categories of carbon changes: inputs and outputs of both live and dead carbon pools, to assess their relative contributions to and uncertainty of terrestrial carbon cycle feedbacks. Because the processes that control carbon inputs to ecosystems are essentially distinct from those that control carbon outputs from ecosystems, this disaggregation can be used to better infer the controls on carbon changes. At the same time, there are observed negatively correlated relationships between carbon inputs and turnover times in both live and dead carbon pools. Evidence for this is that live biomass saturates under gradients of increasing productivity across a range of ecosystems (Malhi et al., 2004; Keeling and Phillips, 2007), and soil carbon does as well (Six et al., 2002; Schmidt et al., 2011). While the mechanisms behind these relationships differ greatly between live and dead pools, such relationships imply tradeoffs between productivity and turnover for both ecosystem components. Thus, in addition to separating the productivity and turnover controls, we are interested in whether any such tradeoffs can be found in ESM projections in response to elevated $\mathrm{CO}_{2}$ and climate change, and if so, what both their mechanistic basis and effect on overall carbon feedbacks may be. 


\section{Methods}

\subsection{Separation of turnover and productivity controls in terrestrial models}

The total carbon at a given location $\left(\mathrm{kg} \mathrm{C} \mathrm{m}^{-2}\right)$ can be represented by a simple system that consists of two components, the live vegetation and the dead litter and soil carbon mass:

$\mathrm{C}_{\mathrm{t}}=\mathrm{C}_{1}+\mathrm{C}_{\mathrm{d}}$,

where $\mathrm{C}_{\mathrm{t}}$ is the total ecosystem carbon, $\mathrm{C}_{1}$ is the carbon in live vegetation biomass, and $\mathrm{C}_{\mathrm{d}}$ is the carbon in dead pools, which consists of litter, coarse woody debris (CWD), and soil organic matter (SOM). Models disaggregate the primary live and dead carbon pools in different ways, but this top-level distinction is common to all terrestrial carbon modeling approaches.

The rate of change of carbon in live vegetation pools, $\mathrm{C}_{1}$, can be represented as:

$$
\begin{aligned}
\frac{\mathrm{dC}_{1}}{\mathrm{~d} t} & =\left(f_{\mathrm{gpp}}-f_{\mathrm{Ra}}\right)-f_{\text {mortality }} \\
\frac{\mathrm{dC}}{\mathrm{d} t} & =\left(f_{\mathrm{gpp}}-f_{\mathrm{Ra}}\right)-\frac{\mathrm{C}_{1}}{\tau_{1}} \\
\frac{\mathrm{d} C_{1}}{\mathrm{~d} t} & =f_{\mathrm{npp}}-\frac{\mathrm{C}_{\mathrm{l}}}{\tau_{1}},
\end{aligned}
$$

where $f_{\text {gpp }}$ is gross primary productivity, $f_{\text {npp }}$ is net primary productivity, and $f_{\mathrm{Ra}}$ is autotrophic respiration, all in units of $\mathrm{kg} \mathrm{C} \mathrm{m}{ }^{-2} \mathrm{yr}^{-1}$. The litterfall and other losses, including fire, mortality, or root exudates if they are represented, are aggregated as $f_{\text {mortality }}$ and represented on the basis of a turnover time $\tau_{1}$, as $\frac{\mathrm{C}_{1}}{\tau_{1}}$, which assumes that such losses can be represented as a first-order process. At steady state, $\frac{\mathrm{dC}_{1}}{\mathrm{~d} t}=0$, which yields the equilibrium vegetation carbon pool, designated here as $\widehat{\mathrm{C}}_{l}$, which is defined as:

$\widehat{\mathrm{C}_{1}}=f_{\mathrm{npp}} \tau_{1}$.

Note that we are distinguishing here between the realized live carbon stock $\mathrm{C}_{1}$, and the equilibrium carbon stock $\widehat{\mathrm{C}}_{\mathrm{l}}$. When the system is at steady state, $\mathrm{C}_{1}=\widehat{\mathrm{C}}_{\mathrm{l}}$, and Eq. (5) holds true for the actual live carbon stock as well. When the system is not at steady state, $\widehat{\mathrm{C}}_{1}$ describes the value that the live carbon stock $\mathrm{C}_{1}$ would eventually attain if $f_{\mathrm{npp}}$ and $\tau_{1}$ were held constant for a sufficiently long period.

Note that the above approach considers the net primary productivity $\left(f_{\mathrm{npp}}\right)$ as inputs, by grouping together the gross productivity $\left(f_{\mathrm{gpp}}\right)$ and autotrophic respiration $\left(f_{\mathrm{Ra}}\right)$. The reason we make the separation between productivity and turnover there is because the bulk of carbon respired autotrophically passes quickly through the plants back to the atmosphere, so that grouping $f_{\mathrm{Ra}}$ with $f_{\mathrm{gpp}}$ allows us to align the productivity/turnover distinction as a separation between fast timescale processes (photosynthesis and autotrophic respiration) and slower timescale processes (growth, mortality, and litterfall). One could alternatively treat the gross productivity as the inputs (e.g., Carvalhais et al., 2014); our reported turnover times will be longer than those calculated using $f_{\mathrm{gpp}}$ as the input flux.

For dead carbon pools, the rate of change of carbon for $C_{d}$ is similarly represented as:

$$
\begin{aligned}
& \frac{\mathrm{d} C_{\mathrm{d}}}{\mathrm{d} t}=f_{\mathrm{l} \rightarrow \mathrm{d}}-f_{\mathrm{Rh}} \\
& \frac{\mathrm{d} \mathrm{C}_{\mathrm{d}}}{\mathrm{d} t}=f_{\mathrm{l} \rightarrow \mathrm{d}}-\frac{\mathrm{C}_{\mathrm{d}}}{\tau_{\mathrm{d}}}
\end{aligned}
$$

and the equilibrium dead carbon stock:

$\widehat{\mathrm{C}_{\mathrm{d}}}=f_{1 \rightarrow \mathrm{d}} \tau_{\mathrm{d}}$,

where $\tau_{\mathrm{d}}$ is the effective turnover time of the dead carbon pools, which is used to approximate heterotrophic respiration $\left(f_{\mathrm{Rh}}=\frac{\mathrm{C}_{\mathrm{d}}}{\tau_{\mathrm{d}}}\right)$, and $f_{\mathrm{l} \rightarrow \mathrm{d}}$ is the total litterfall and background mortality flux from live to dead pools. $f_{1 \rightarrow \mathrm{d}}$ is either equal to or smaller than $f_{\text {mortality }}$, because a fraction of the mortalitydriven carbon flux may be lost to the atmosphere without being transferred to the dead pools, for example by burning.

The CMIP5 experimental protocol requires that the models are initially run until approximate steady-state, for preindustrial conditions, so equilibrium values can be approximated as those obtained from the model output corresponding to the pre-industrial control simulation, i.e., initially $\widehat{\mathrm{C}_{1}} \approx \mathrm{C}_{1}$ and $\widehat{\mathrm{C}_{\mathrm{d}}} \approx \mathrm{C}_{\mathrm{d}}$. Furthermore, for the CMIP5 models, $\tau_{1}$ and $\tau_{\mathrm{d}}$ are not reported directly, but can be calculated as the ratio of carbon stocks to the total output fluxes from those carbon stocks:

$$
\begin{aligned}
\tau_{1} & =\frac{\mathrm{C}_{1}}{f_{\text {mortality }}} \\
\tau_{\mathrm{d}} & =\frac{\mathrm{C}_{\mathrm{d}}}{f_{\mathrm{Rh}}},
\end{aligned}
$$

where $f_{\text {mortality }}$ are the total mortality fluxes (equal to $f_{1 \rightarrow \mathrm{d}}$ plus fire fluxes, if calculated, as well as harvest fluxes if land-use were to be considered in a given model experiment, though it is not here), and $f_{\mathrm{Rh}}$ is the total heterotrophic respiration arising from decomposition of the dead pools. For fire fluxes, a component of these may also come from litter and CWD pools, but for simplicity we assume here that all fire-related fluxes are generated from the live pools. Note that in all cases here, $\tau$ is calculated based on the outputs from a given set of pools, not the inputs to those pools; while the two are equal by definition at steady-state, the use of input fluxes 
to calculate $\tau$ under non-steady-state conditions would lead to errors.

Under transient global change conditions, the pool sizes are perturbed due to changes in inputs and outputs of the respective pools, i.e., $f_{\text {npp }}$ and $f_{\text {mortality }}$ for $\mathrm{C}_{1}$, and $f_{1 \rightarrow \mathrm{d}}$ and $f_{\mathrm{Rh}}$ for $\mathrm{C}_{\mathrm{l}}$. In order to calculate the relative roles of carbon inputs and losses to these pools, we can calculate the instantaneous change to equilibrium carbon pools $\widehat{\mathrm{C}_{1}}$ and $\widehat{\mathrm{C}_{\mathrm{d}}}$ by differentiating Eqs. (5) and (8) above:

$$
\begin{aligned}
\frac{\mathrm{d} \widehat{\mathrm{C}}_{\mathrm{l}}}{\mathrm{d} t} & =\frac{\mathrm{d} f_{\mathrm{npp}}}{\mathrm{d} t} \tau_{1}+\frac{\mathrm{d} \tau_{1}}{\mathrm{~d} t} f_{\mathrm{npp}} \\
\frac{\mathrm{d} \widehat{\mathrm{C}_{\mathrm{d}}}}{\mathrm{d} t} & =\frac{\mathrm{d} f_{1 \rightarrow \mathrm{d}}}{\mathrm{d} t} \tau_{\mathrm{d}}+\frac{\mathrm{d} \tau_{\mathrm{d}}}{\mathrm{d} t} f_{\mathrm{l} \rightarrow \mathrm{d}} .
\end{aligned}
$$

The first and second terms of the right-hand side of Eqs. (11) and (12) are the production-driven and turnover-driven terms, respectively, for the instantaneous changes of each of the equilibrium terrestrial pools. If we make the assumption that these instantaneous changes can be extended over a finite period of time, (ignoring higher-order terms for the sake of simplicity) we can compare the actual model-predicted carbon changes $\left(\Delta C_{1}\right.$ and $\left.\Delta C_{d}\right)$ to the linearized equilibrated changes $\left(\Delta \widehat{\mathrm{C}_{1}}\right.$ and $\left.\Delta \widehat{\mathrm{C}_{\mathrm{d}}}\right)$, calculated as:

$$
\begin{aligned}
& \Delta \widehat{\mathrm{C}_{1}}=\Delta f_{\mathrm{npp}} \tau_{1,0}+\Delta \tau_{1 f_{\mathrm{npp}, 0}} \\
& \Delta \widehat{\mathrm{C}_{\mathrm{d}}}=\Delta f_{1 \rightarrow \mathrm{d}} \tau_{\mathrm{d}, 0}+\Delta \tau_{\mathrm{d}} f_{1 \rightarrow \mathrm{d}, 0},
\end{aligned}
$$

where $\Delta f_{\mathrm{npp}}, \Delta f_{\mathrm{l} \rightarrow \mathrm{d}}, \Delta \tau_{\mathrm{l}}$, and $\Delta \tau_{\mathrm{d}}$ are the changes over the model run and $f_{\mathrm{npp}, 0}, f_{1 \rightarrow \mathrm{d}, 0}, \tau_{1,0}$, and $\tau_{\mathrm{d}, 0}$ are the initial values for each of the corresponding terms at the end of the preindustrial period. This is an extension of the method at estimating carbon sinks developed originally by Taylor and Lloyd (1992) that assumes a constant $\tau$; here we are interested in the relative magnitudes of, and relationships between, the productivity- and turnover-driven terms. The primary advantages of examining the equilibrium carbon responses to changed productivity vs. turnover, rather than simply looking at changes to productivity vs. turnover on their own, are that doing so allows comparison of (1) the relative magnitudes of these processes in consistent units, and (2) the carbon impacts of these changes between models and between geographic regions within models. These comparisons are not possible if one just examines changes in the driving terms in isolation, as, e.g., a unit change of $f_{\text {npp }}$ or $\tau_{1}$ will have a different impact on the equilibrium carbon stock at high latitudes than in the tropics, as well as based on the underlying assumptions unique to each model.

The linearization approach used here may be expected to give substantial errors as compared to the actual model predictions, for reasons that include the aggregation of all pools and fluxes into just the set of live and dead pools and input and output fluxes, as well as errors arising from approximating the complex time evolution as a set of simple linear responses. More accurate methods could be applied to this problem, for example diagnosing the many individual pool stocks and turnover times (Xia et al., 2013) to better trace the evolution of a given model. Despite these limitations, the approach here allows insight into the differences in carbon cycle feedback behavior of a diverse ensemble of fully coupled ESMs.

\subsection{Application to CMIP5}

The CMIP5 protocol specified a set of idealized forcing experiments. In one of these experiments, the specified atmospheric $\mathrm{CO}_{2}$ concentration increases by $1 \% \mathrm{yr}^{-1}$ until quadrupling. There are no other forcings in this experiment, such as land-use or other anthropogenic greenhouse gasses. The participating models performed fully, biogeochemically and radiatively coupled versions of this experiment, in which either or both the atmospheric radiation components or the terrestrial and oceanic biogeochemistry components of the models respond to increasing $\mathrm{CO}_{2}$ (Taylor et al., 2012). These experiments have also been used to determine the carbon cycle feedback terms $\beta$ and $\gamma$ (Arora et al., 2013). Here, we use these experiments to disaggregate the responses of the productivity and turnover controls on changes in carbon pools to radiative and biogeochemical responses to rising $\mathrm{CO}_{2}$ to better understand their controls and interactions. We first describe the response in the fully coupled experiment, and then each of the single-coupled experiments to partition the responses to their respective forcings.

The five models that participated in CMIP5 and reported sufficient information to calculate the terms outlined above for each of the $1 \% \mathrm{CO}_{2} \mathrm{yr}^{-1} \mathrm{ESM}$ experiments are: CESM1-BGC, CanESM2, HadGEM2-ES, IPSL-CM5A-LR, and MPI-ESM (Table 1). Changes to the pools and turnover times are calculated by first smoothing all variables (for 15 years) to remove high-frequency fluctuations, and then differencing the initial conditions from the conditions when $\mathrm{CO}_{2}$ reaches double its pre-industrial values (72 years). We assume the models are initially in a long-term steady state at the start of the experiments, as specified in the CMIP protocol, and do not test explicitly for initial steady-state conditions. These models, while state of the art, may have fundamental biases, as evidenced by their performance against a broad suite of benchmarks (Anav et al., 2013), and the wide range of predictions of current atmospheric $\mathrm{CO}_{2}$ levels in the historical period when using an emissions-driven carbon cycle (Hoffman et al., 2014).

\section{Results and Discussion}

\subsection{Initial distributions of productivity and turnover}

Models generally agree on the basic amounts and distributions of productivity $f_{\mathrm{npp}}$, though differences among the models are apparent, particularly in tropical forests, where 
Table 1. Models used in this analysis, key references for each model, and some basic info: whether or not the models consider dynamic vegetation distributions; whether allocation of carbon to vegetation pools is dynamic or static; and the number of litter, coarse woody debris (CWD) and soil organic matter (SOM) pools that constitute the dead carbon stocks.

\begin{tabular}{|c|c|c|c|c|c|}
\hline ESM & Land model & Reference(s) & DGVM & Dynamic allocation & $\begin{array}{l}n \text { Dead } \\
\text { Pools }\end{array}$ \\
\hline CESM1-BGC & CLM4.0 & Oleson et al. (2010) & No & Thornton et al. (2007) & 7 \\
\hline CanESM2 & CTEM1 & Arora et al. (2011) & No & Yes & 2 \\
\hline HadGEM2 & MOSES/TRIFFID & Cox (2001); Jones et al. (2011) & Yes & Yes & 4 \\
\hline IPSL-CM5A & ORCHIDEE & Krinner et al. (2005) & No & Friedlingstein et al. (1999) & 7 \\
\hline MPI-ESM & JSBACH & $\begin{array}{l}\text { Raddatz et al. (2007); Brovkin et al. (2009); } \\
\text { Reick et al. (2013) }\end{array}$ & Yes & No & 2 \\
\hline
\end{tabular}

models disagree on the relative productivity of forests on different continents, and at high latitudes, where models disagree on the rate at which productivity declines towards the northern high latitudes (left column of Fig. 1). The input fluxes $f_{\text {npp }}$ and $\mathrm{f}_{\mathrm{l} \rightarrow \mathrm{d}}$ (second column in Fig. 1) are similar to each other, as expected given that land-use and harvest are not considered in these runs and therefore their difference is due only to fire. For turnover (right two columns of Fig. 1), the CMIP5 ESMs do not agree on the basic distribution of either $\tau_{1,0}$ or $\tau_{\mathrm{d}, 0}$. All models agree that $\tau_{1,0}$ is higher in forested than in non-forested ecosystems, but beyond that they disagree; e.g., CESM1 has longer $\tau_{1,0}$ in tropical than boreal forests, while CanESM2 and IPSL-CM5A have longer $\tau_{1,0}$ in boreal than tropical forests and MPI-ESM and HadGEM2-ES have relatively closer $\tau_{1,0}$ between the two forested regions. For the case of CESM1, the model prediction of longer $\tau_{1,0}$ in the tropics is a result of geographical variation in allocation, which increases allocation to wood under high NPP environments (Thornton et al., 2007). For $\tau_{\mathrm{d}, 0}$, the models tend to show longer values at high rather than low latitudes, as expected because low temperatures decrease decomposition rates, though the absolute magnitude of inter-model differences is large. Since none of these models consider permafrost carbon explicitly, these estimates of turnover times at high latitudes are likely underestimations. Given that the magnitudes of $f_{\text {npp }}$ between the models are more uniform, these differences in $\tau_{1,0}$ and $\tau_{\mathrm{d}, 0}$ translate directly to biases in the total stock of $C_{1}$ and $C_{d}$, as has been shown in, e.g., Friedlingstein et al. (2013); Todd-Brown et al. (2013). Previous analyses have shown that total ecosystem turnover times are poorly represented in these models (Carvalhais et al., 2014); here we show that this inter-model uncertainty arises from spread in both the live and dead components of the ecosystems.

\subsection{Responses of live carbon pools to climate and $\mathrm{CO}_{2}$}

To test whether the method described above for calculating changes to equilibrium live carbon stocks $\Delta \widehat{\mathrm{C}}_{1}$ is a reasonable approximation of the actual ESM-predicted live carbon stock changes $\Delta \mathrm{C}_{1}$, we first regress the two against each other for each model and each experimental coupling (Fig. 2). For all models, the linearized equilibrium term $\Delta \widehat{\mathrm{C}}_{1}$ is highly correlated to $\left(r^{2}=0.78-0.93\right)$, but is higher than (regression slope $=0.49-0.80$ ), the magnitude of the realized change $\Delta \mathrm{C}_{1}$ calculated in the full ESM. This result is expected since the full ESM will not have had time to equilibrate under the transient forcing of the scenario. In the fully coupled scenario, and for all models, live carbon stocks increase over most of the globe as a result of the combined climate and $\mathrm{CO}_{2}$ changes. This is true also for the biogeochemically coupled scenario, while the radiatively coupled scenario shows more widespread carbon losses.

Maps of productivity-driven and turnover-driven live carbon change terms $\Delta f_{\text {npp }} \tau_{1,0}$, and $\Delta \tau_{1_{\mathrm{fpp}, 0}}$ for the fully coupled ("1pctCO2") run are shown in Fig. 3. Comparing the two columns (productivity-driven and turnover-driven equilibrium live carbon changes) shows that the bulk of these changes are driven by increased productivity; i.e., the total carbon changes can be well approximated by the product of a fixed initial live carbon turnover time $\left(\tau_{1,0}\right)$ and changing NPP. However there are some exceptions where turnoverdriven changes are also occurring. One model (HadGEM2) shows a large and widespread reduction in $\tau_{1}$ throughout the tropical forests, one model (IPSL-CM5A) shows a small increase in $\tau_{1}$ in the African tropical forest region, and one model (MPI-ESM) shows a reduction in turnover-driven carbon in tropical savannah regions and increases in some rainforest regions; the other two models show only weak changes to the turnover-driven equilibrium carbon stocks as a result of the forcing. All models show increases in the productivitydriven equilibrium live carbon change term. Comparing the productivity and turnover-driven terms directly against each other (Fig. 4) shows that they are highly correlated for only one model, HadGEM2-ES $\left(r^{2}=0.68\right.$ and regression slope $=-0.36$ for the fully coupled $1 \mathrm{pctCO} 2$ run).

In the biogeochemically coupled ("esmFixClim1") run, in which $\mathrm{CO}_{2}$ fertilization operates without the radiative forcing from $\mathrm{CO}_{2}$, the response (Fig. 5) is qualitatively similar to the fully coupled run: live carbon pools increase virtually everywhere, driven by increased NPP. Interestingly, the same basic relationship with turnover-driven live carbon changes is 


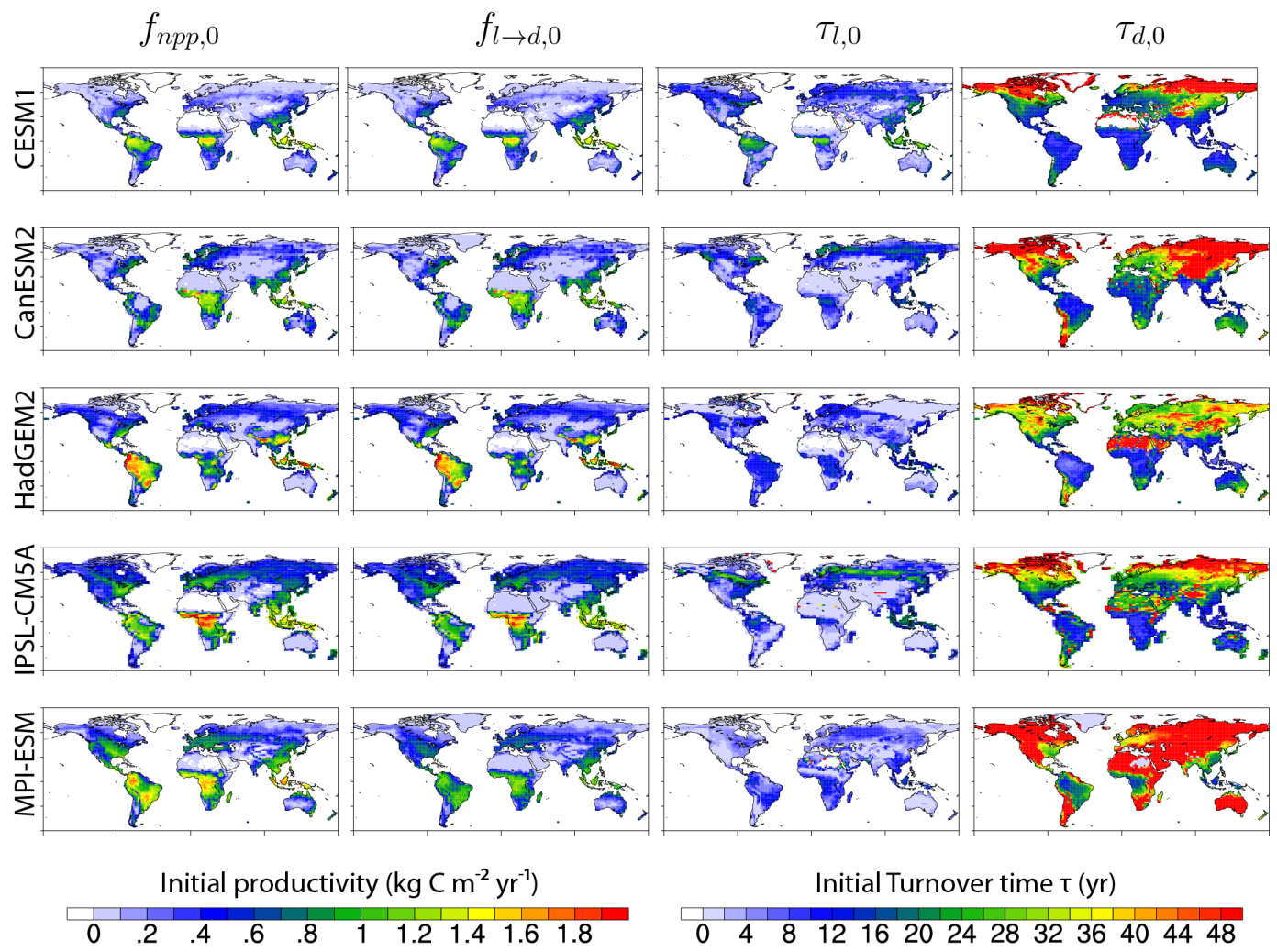

Figure 1. Comparison of initial (preindustrial) productivity $\left(\mathrm{kg} \mathrm{C} \mathrm{m}^{-2} \mathrm{yr}^{-1}\right)$ and turnover times (yr) for both the live and dead carbon pools in the models. Columns, from left to right, show $f_{\mathrm{npp}}, f_{1 \rightarrow \mathrm{d}, 0}, \tau_{1,0}$, and $\tau_{\mathrm{d}, 0}$. Model agreement is generally higher on initial productivity than either of the turnover times, in which models disagree on both the magnitude and fundamental geographic patterns.

found as well: HadGEM2 shows a reduction in the live carbon turnover times pantropically, while IPSL-CM5A shows an increase in the African rainforest. In response to the radiative forcing in the absence of $\mathrm{CO}_{2}$ fertilization of the radiatively coupled ("esmFdbk1") run (Fig. 6), live carbon decreases are widespread; as with the $\mathrm{CO}_{2}$ fertilization-driven carbon increases, these decreases are largest in the tropical forest regions and driven mainly by changes to productivity. Four of the models show reduced $f_{\text {npp }}$ in the tropics and increased $f_{\text {npp }}$ in the boreal zone, following the basic pattern proposed by Fung et al. (2005), which explain most of the changes to $C_{1}$ under changing climate. The climatedriven changes to live carbon turnover times now show an increase in turnover-driven carbon in the tropical forests in HadGEM2, the opposite of the $\mathrm{CO}_{2}$ fertilization and fully coupled runs. As in the fully coupled runs, only one model (MPI-ESM) shows reductions in turnover-driven live carbon changes in the tropical savannah region. Regressing the productivity-driven and turnover-driven live carbon changes against each other for the singly-coupled runs (second and third columns of Fig. 4), the regression lines are mostly similar to the fully coupled run, although the phase-space sampled under the different forcings is different: in all cases, only one model (HadGEM2) shows a strong regression relation- ship, and its slope is consistently negative. The other models show either no relationship or a weak one.

In order to understand the relationships between changing turnover and productivity, we first consider the controls on $\tau_{1}$. In forest ecosystems, leaves and fine roots consume a large fraction of NPP, but contribute little to biomass, because their short turnover times mean that they are constantly contributing to the litter pool. Instead, the biomass is dominated by wood, which has a much longer turnover time than leaves and fine roots. As a result, $\tau_{1}$ can be approximated:

$\tau_{1} \approx p_{\text {wood }} \tau_{\text {wood }}$,

where $p_{\text {wood }}$ is the proportion of NPP that is allocated to woody tissues (trunk and coarse roots), and $\tau_{\text {wood }}$ is the turnover time of woody tissues, which is largely dominated by the mortality of individual trees. Thus, changes to either allocation $\left(p_{\text {wood }}\right)$ or mortality $\left(\tau_{\text {wood }}\right)$ can give rise to changes in $\tau_{1}$. For these models, both processes are highly parameterized: since none of these models include individual tree or cohort dynamics, mortality is typically treated as a constant background rate with possible disturbancerelated additions, and allocation is treated either statically or as a simple functional relationship. In the simulations shown here, different processes drive the turnover-driven live car- 

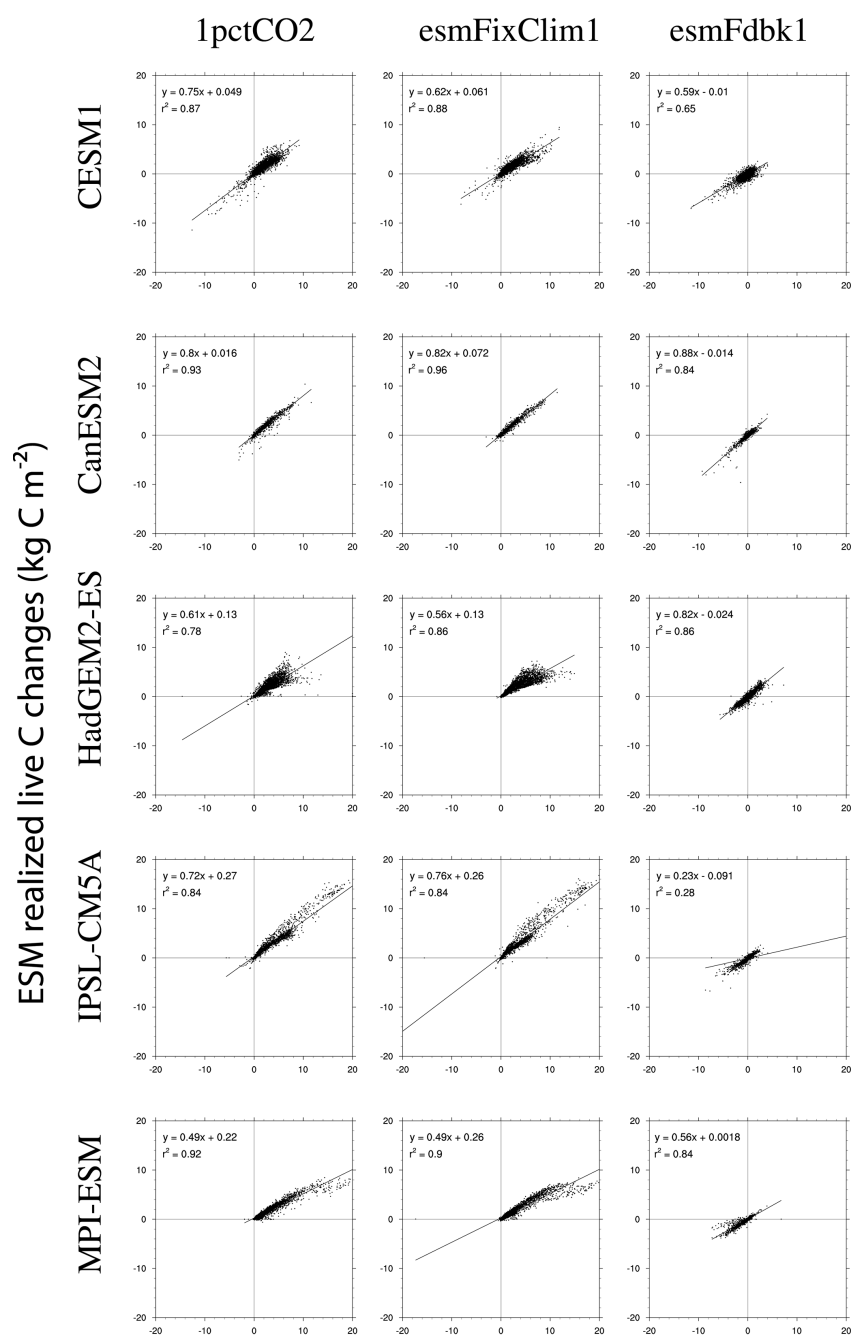

Linearized equilibrium live $\mathrm{C}$ changes $\left(\mathrm{kg} \mathrm{C} \mathrm{m}^{-2}\right)$

Figure 2. Scatterplots of linearized equilibrium live carbon pool changes (Eq. 13) versus actual ESM-predicted realized live carbon changes for each model and scenario.

bon changes in different models. For the HadGEM2 case, the reduction in turnover times with increasing productivity is explained by allocation of a fraction of NPP for a spatial expansion in the TRIFFID dynamic vegetation module (Cox, 2001): when a given PFT occupies a small fraction of a grid cell, the fraction of NPP allocated for spatial expansion is used to increase the fractional coverage. However, when a PFT is already covering a larger fraction of a gridcell, then the fraction of NPP allocated for spatial expansion is instead routed to the litter pools. Thus HadGEM2 implicitly represents a density-dependent reduction in turnover times that occurs through its representation of dynamic allocation. We note as well that HadGEM2 is the only CMIP5 model that shows a saturating relationship of biomass as a function of productivity in the current climate (Negrón-Juárez et al.,

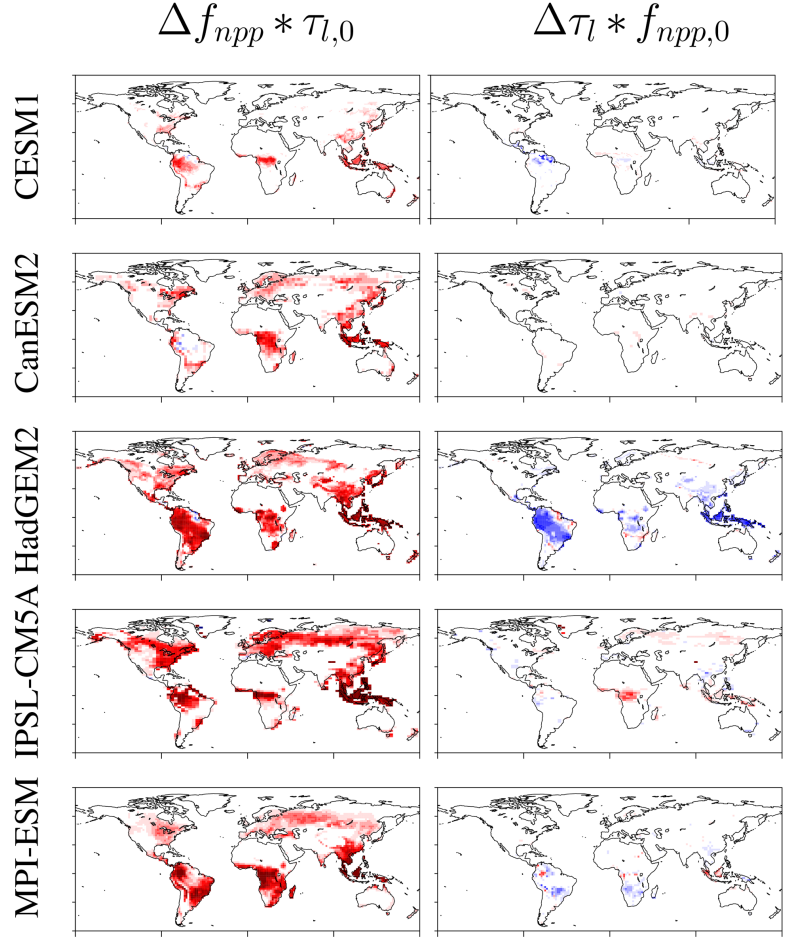

Fully-coupled Live Carbon Change $\left(\mathrm{kg} \mathrm{C} / \mathrm{m}^{2}\right)$ $\begin{array}{llllllllllll}-10 & -8 & -6 & -4 & -2 & 0 & 2 & 4 & 6 & 8 & 10\end{array}$

Figure 3. Responses of linearized equilibrium live carbon pools ( $\mathrm{kg} \mathrm{C} \mathrm{m}{ }^{-2}$ over the interval of $\mathrm{CO}_{2}$ doubling) in fully coupled (1pctCO2) run. Left column shows productivity-driven changes to $\widehat{\mathrm{C}_{\mathrm{l}}}$. Right column shows turnover-driven changes to $\widehat{\mathrm{C}_{1}}$.

2015), as is observed along spatial productivity gradients (Keeling and Phillips, 2007). For IPSL-CM5A, the increase in turnover times in some areas also appears to be driven by a change in the allocation from roots to wood in response to changing resource limitations (Friedlingstein et al., 1999). For MPI-ESM, reductions in turnover times of tropical savannas are driven by increasing fire frequency. In none of the models does mortality by processes such as drought-which would manifest in this analysis as a reduction in both live carbon turnover times and productivity-play a major role in carbon changes; this result supports recent analyses that the model responses of tree mortality to global change are too weak (Powell et al., 2013).

The control of carbon changes by productivity versus turnover has been previously investigated in several studies (e.g., Matthews et al., 2005; Friend et al., 2014) and appears to be strongly influenced by the choice and structure of models. The collection of models used in the CMIP5 carbon cycle experiments appear to differ from those used in Friend et al. (2014), which had a wider range of dynamical vegetation processes represented, and therefore showed a stronger control on live carbon responses by changes to 

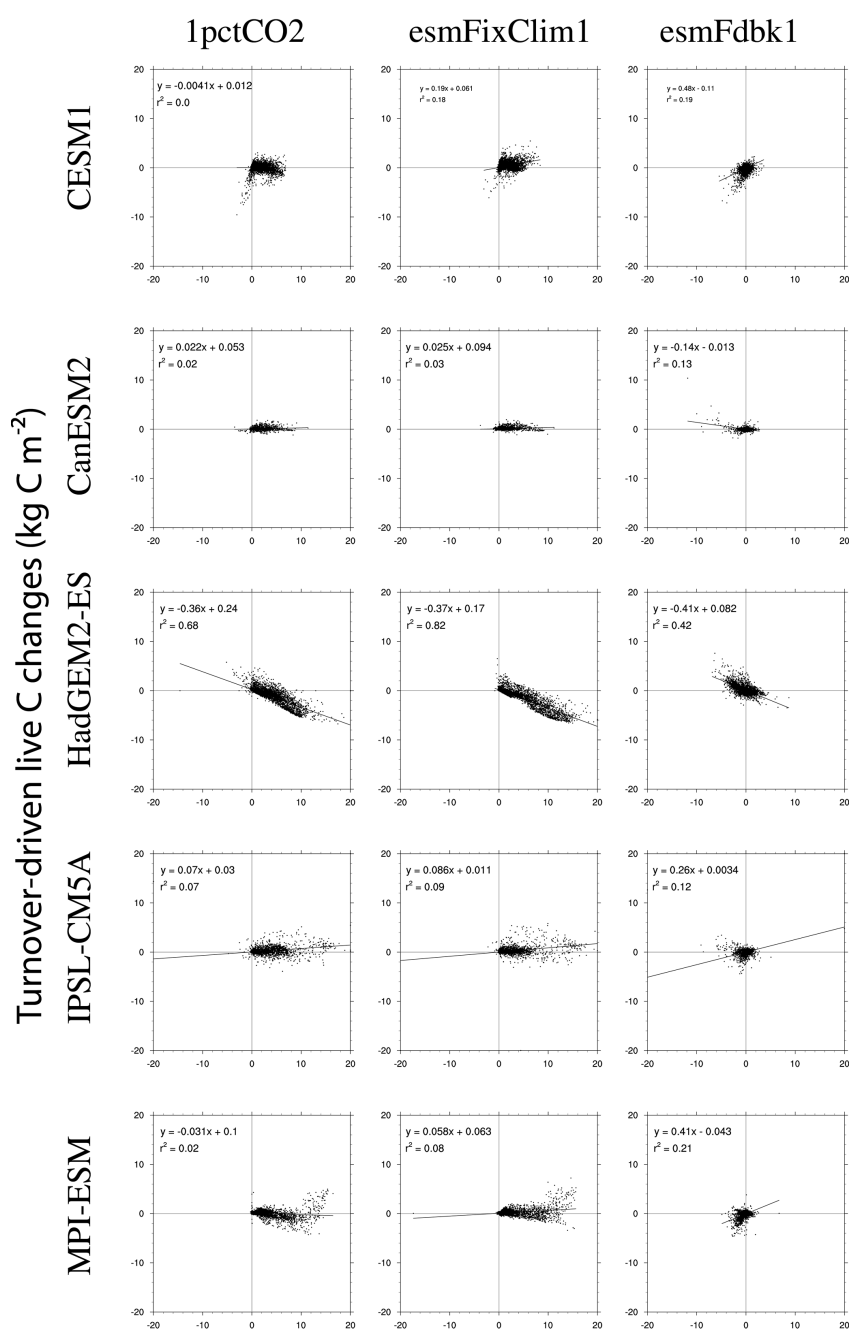

Productivity-driven live $\mathrm{C}$ changes $\left(\mathrm{kg} \mathrm{C} \mathrm{m}^{-2}\right)$

Figure 4. Scatterplots of productivity-driven vs. turnover-driven changes to the live pool equilibrium carbon amounts for each model and experiment.

$\tau_{1}$. Here, of the five models considered in the fully coupled run, one (HadGEM2) shows a widespread decrease in $\tau_{1}$ in response to productivity gains, one (IPSL-CM5A) shows a slight increase in $\tau_{1}$ with productivity gains, two (CESM1 and MPI-ESM) show some regions with decreasing $\tau_{1}$ and other regions with increasing $\tau_{1}$, and one (CanESM2) shows almost no change in $\tau_{1}$. In real forest ecosystems, a tradeoff appears to exist between live carbon productivity and turnover times through a combination of changes to allocation and mortality, as evidenced by a saturation of biomass across spatial gradients of productivity (Malhi et al., 2004; Keeling and Phillips, 2007). Multiple hypotheses have been proposed to explain these tradeoffs (Stephenson et al., 2011; Malhi, 2012), and the empirical productivity-mortality relationships can be specified in terrestrial models (Delbart et al.,

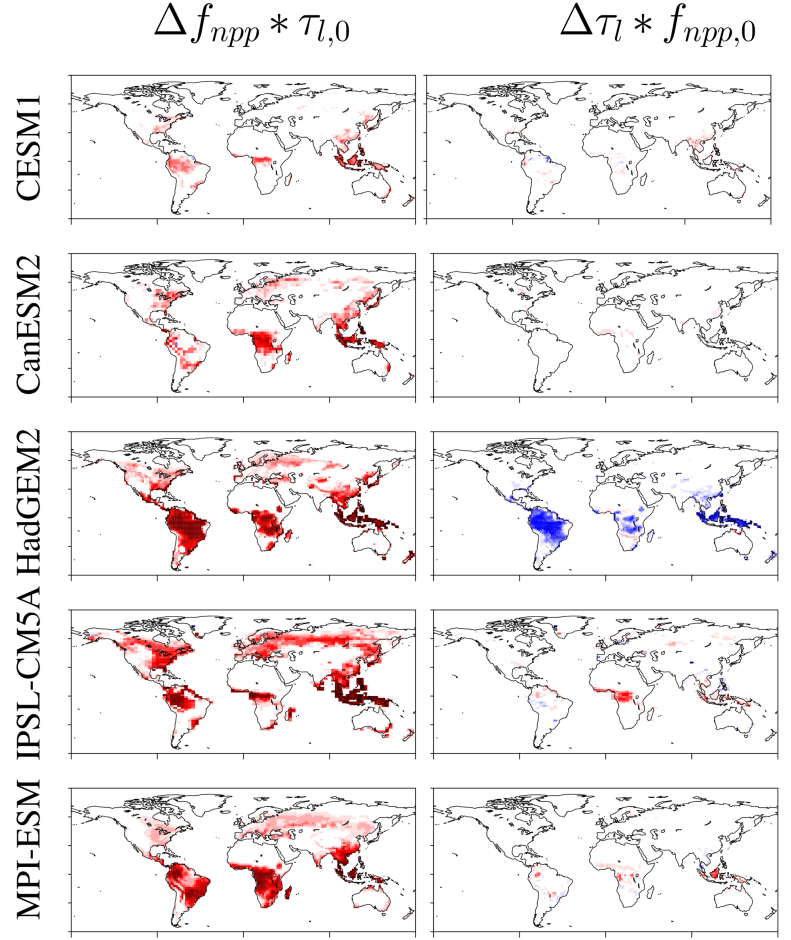

BGC-Coupled Live Carbon Change $\left(\mathrm{kg} \mathrm{C} / \mathrm{m}^{2}\right)$

$\begin{array}{lllllllllll}-10 & -8 & -6 & -4 & -2 & 0 & 2 & 4 & 6 & 8 & 10\end{array}$

Figure 5. Responses of linearized equilibrium live carbon pools ( $\mathrm{kg} \mathrm{C} \mathrm{m}^{-2}$ over the interval of $\mathrm{CO}_{2}$ doubling) in biogeochemically coupled (esmFixClim1) run. Left column shows productivity-driven changes to $\widehat{\mathrm{C}_{1}}$. Right column shows turnover-driven changes to $\widehat{\mathrm{C}_{1}}$.

2010), but a key question is whether similar tradeoffs to what is observed along spatial gradients occur also in temporal responses of ecosystems to changing productivity, e.g., by $\mathrm{CO}_{2}$ fertilization. Most of the CMIP5 models do not include the processes behind the former, nor do they include the possibility of the latter. In reality, tropical forests appear to be shifting to a higher-productivity, higher-turnover state that limits carbon accumulation (Brienen et al., 2015), which suggests that these spatially derived patterns may also hold for the transient response to increasing productivity. It is thus critical for models to represent the mechanisms behind changing biomass turnover to accurately project carbon feedbacks to global change.

\subsection{Responses of dead carbon pools to climate and $\mathrm{CO}_{2}$}

To test whether the method described above for calculating changes to equilibrium dead carbon stocks $\Delta \widehat{\mathrm{C}_{\mathrm{d}}}$ is a reasonable approximation of the actual ESM-predicted dead carbon stock changes $\Delta \mathrm{C}_{\mathrm{d}}$, we next regress the two against each other for each model and each experimental coupling (Fig. 7). It is apparent that, though the approximation still 


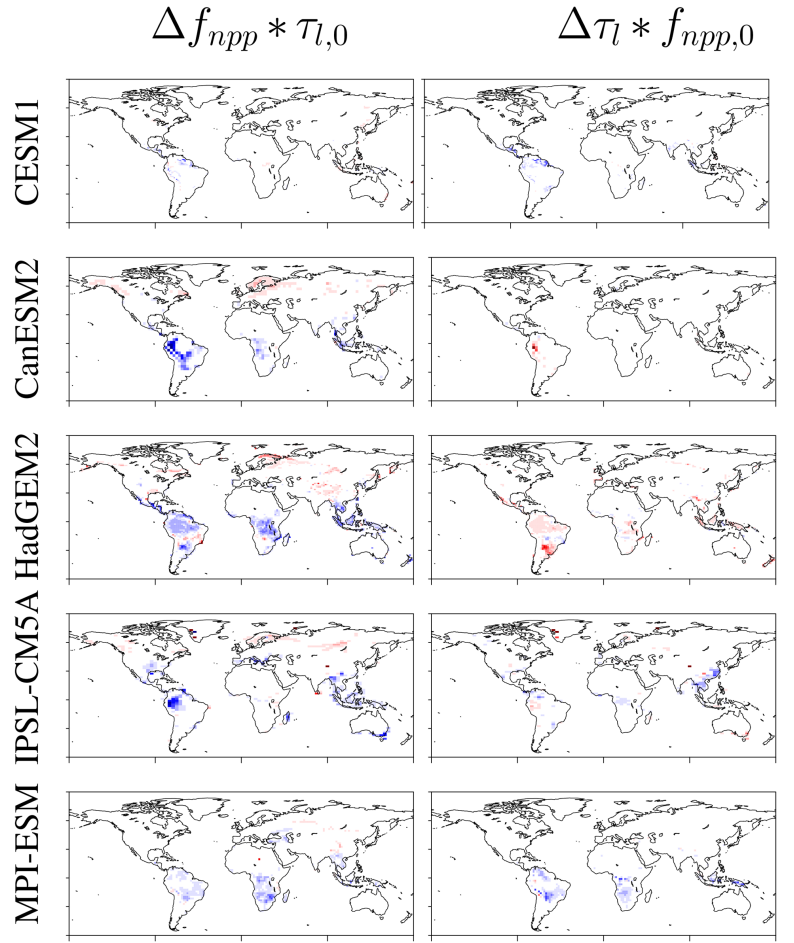

Rad.-Coupled Live Carbon Change $\left(\mathrm{kg} \mathrm{C} / \mathrm{m}^{2}\right)$
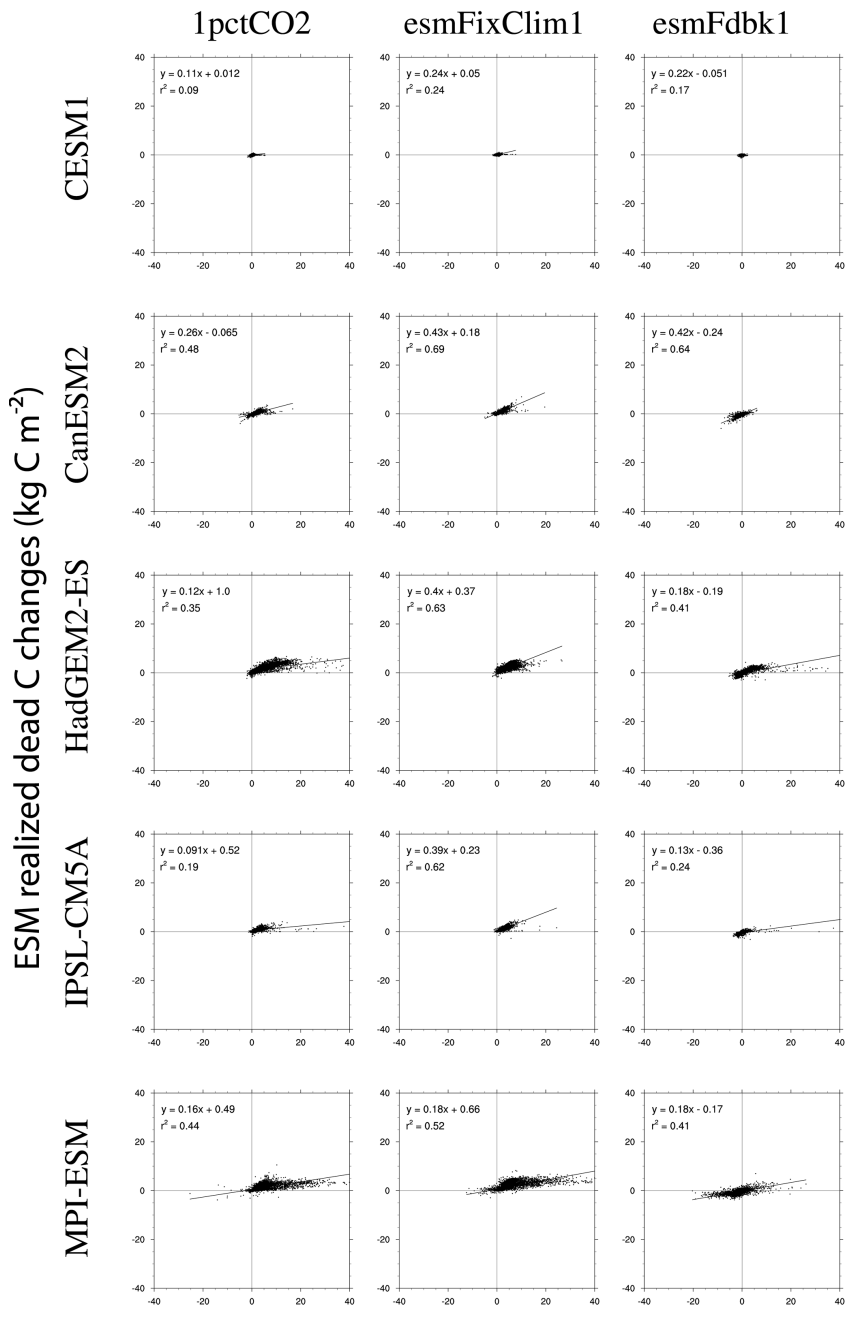

Linearized equilibrium dead $\mathrm{C}$ changes $\left(\mathrm{kg} \mathrm{C} \mathrm{m}^{-2}\right)$

Figure 7. Scatterplots of linearized equilibrium dead carbon pool changes (Eq. 14) versus actual ESM-predicted realized dead carbon changes for each model and scenario.

as good as with the live carbon changes. This can be seen both as wider scatter between the two terms $\left(r^{2}=0.09\right.$ $0.69)$, as well as a greater degree of overestimation of $\Delta \widehat{\mathrm{C}_{\mathrm{d}}}$ relative to $\Delta C_{d}$ (regression slopes $=0.09-0.43$ ). The reduced explanatory power and lower slopes follow from the longer turnover times of dead carbon relative to live carbon (Fig. 1), as well as the wider geographic range of dead carbon turnover times in each model, which leads to a larger variation in the degree to which the realized dead carbon changes $\Delta \mathrm{C}_{\mathrm{d}}$ have been able to relax towards the equilibrium dead carbon changes $\Delta \widehat{\mathrm{C}_{\mathrm{d}}}$. As with the live carbon pools, the dead carbon pools also tend to increase in response to the combination of $\mathrm{CO}_{2}$ fertilization alone and in combination with climate change, and with more of a balance between gains and losses from climate change alone.

Comparing the geographical distribution of the productivity-driven $\left(\Delta f_{1 \rightarrow \mathrm{d}} \tau_{\mathrm{d}, 0}\right)$ and turnover-driven $\left(\Delta \tau_{\mathrm{d}} f_{1 \rightarrow \mathrm{d}, 0}\right)$ changes to the dead carbon pools (Fig. 8), they show very similar spatial patterns but of opposite sign, with turnover-driven losses partially offsetting productivity- driven carbon gains in the fully coupled experiment. The high degree of correspondence in the spatial patterns of these maps can be further seen by regressing the terms against each other (left column of Fig. 9), to show that there is a clear anticorrelation in all models between changes in the productivity-driven and the turnover-driven terms $\left(r^{2}=0.25-0.89\right.$ and regression slope of -0.12 to -0.67 , with four of five models having $r^{2}>0.5$ and slope $<-0.3$ ).

This pattern of negatively correlated productivity-driven and turnover-driven dead carbon pools appears again in the biogeochemically coupled experiment (Fig. 10) and the radiatively coupled experiment (Fig. 11). Regressing the two terms against each other for these singly-coupled experiments (middle and right columns of Fig. 9) shows a similar slope as in the fully coupled experiment. Where inputs to the dead pools go up, turnover times go down, and vice versa, 


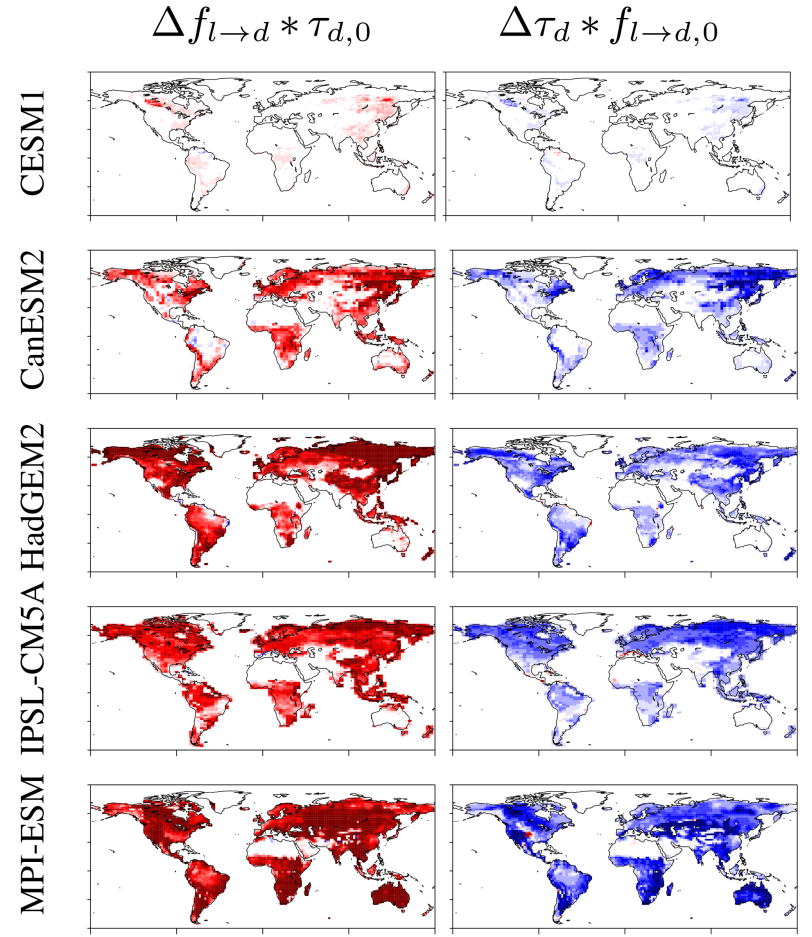

Fully-Coupled Dead Carbon Change $\left(\mathrm{kg} \mathrm{C} / \mathrm{m}^{2}\right)$

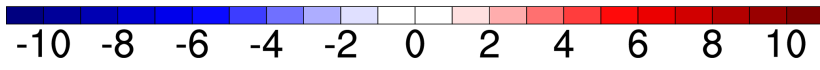

Figure 8. Responses of linearized equilibrium dead (soil and litter) carbon pools $\left(\mathrm{kg} \mathrm{C} \mathrm{m}^{-2}\right.$ over the interval of $\mathrm{CO}_{2}$ doubling) in fully coupled (1pctCO2) run. Left column shows productivitydriven changes to $\widehat{\mathrm{C}_{\mathrm{d}}}$. Right column shows turnover-driven changes to $\widehat{\mathrm{C}_{\mathrm{d}}}$.

under all three forcing scenarios. Furthermore, the turnover times of soil carbon appear to decrease more in response to $\mathrm{CO}_{2}$ fertilization than to climate change.

To interpret the mechanism behind this anticorrelation between carbon input to dead carbon pools and turnover time shown in Fig. 8, consider the possible directional flow of information in the models: with two possible exceptions (discussed below), dead pools are purely diagnostic with respect to the vegetation productivity; i.e., they respond to vegetation but cannot feed back except through atmospheric $\mathrm{CO}_{2}$ concentrations. Since these experimental scenarios are all concentration-forced, this macro-scale feedback loop is cut. Two possible local feedbacks from decomposition to productivity are via $\mathrm{N}$ mineralization in the one model that includes a prognostic $\mathrm{N}$ cycle (CESM1-BGC), and via a weak fire feedback as litter may increase fire probability and severity. We can rule out the first feedback mechanism for the four other models that are C-only (and which show the largest changes) and the second feedback mechanism can be ruled out given that the spatial pattern of the response does not show a signature consistent with area burned, i.e., the anticor-
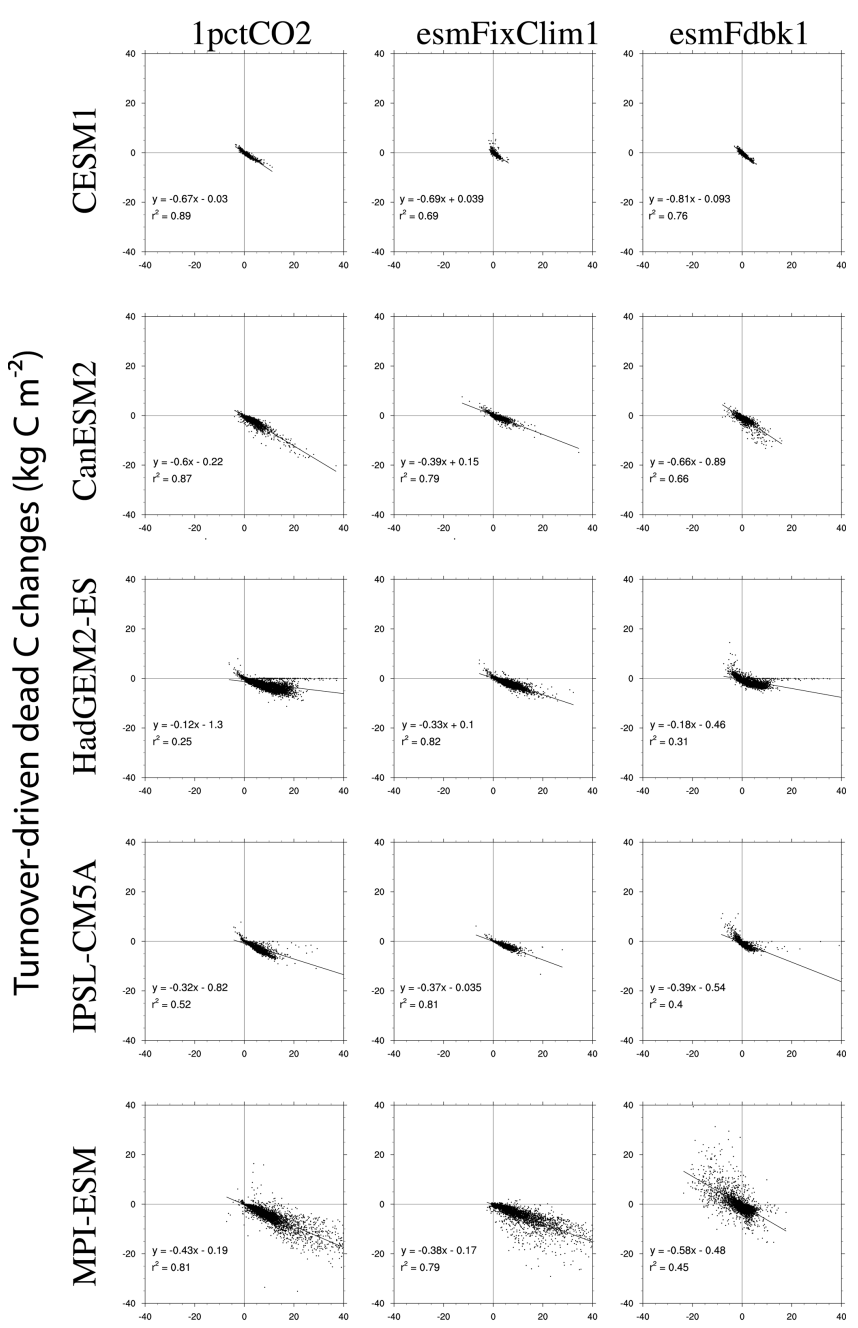

Productivity-driven dead $\mathrm{C}$ changes $\left(\mathrm{kg} \mathrm{C} \mathrm{m}^{-2}\right)$

Figure 9. Scatterplots of productivity-driven vs. turnover-driven changes to the dead pool equilibrium carbon amounts for each model and experiment.

relation occurs in places where burned areas are extremely low, such as intact tropical forests. Thus, the anticorrelation cannot represent a control by the soil and litter pools on productivity; instead, it must either arise from a common response by soils and vegetation across all models and ecosystems to the different global change forcings or from a forced response of the soils to the changing inputs.

The simplest explanation of the anticorrelation is the latter; that the reduction in $\tau_{\mathrm{d}}$ is a forced response to the increased carbon inputs by vegetation. The mechanism by which this occurs is a combination of two conditions: (1) the models are not in steady state at the time of $\mathrm{CO}_{2}$ doubling due to the transient nature of the forcing, and (2) that what we here call $\mathrm{C}_{\mathrm{d}}$ and describe with a single bulk $\tau_{\mathrm{d}}$ is in the models a collection of multiple pools with multiple turnover times, arranged in a cascade from fast-turnover litter pools to slow-turnover 


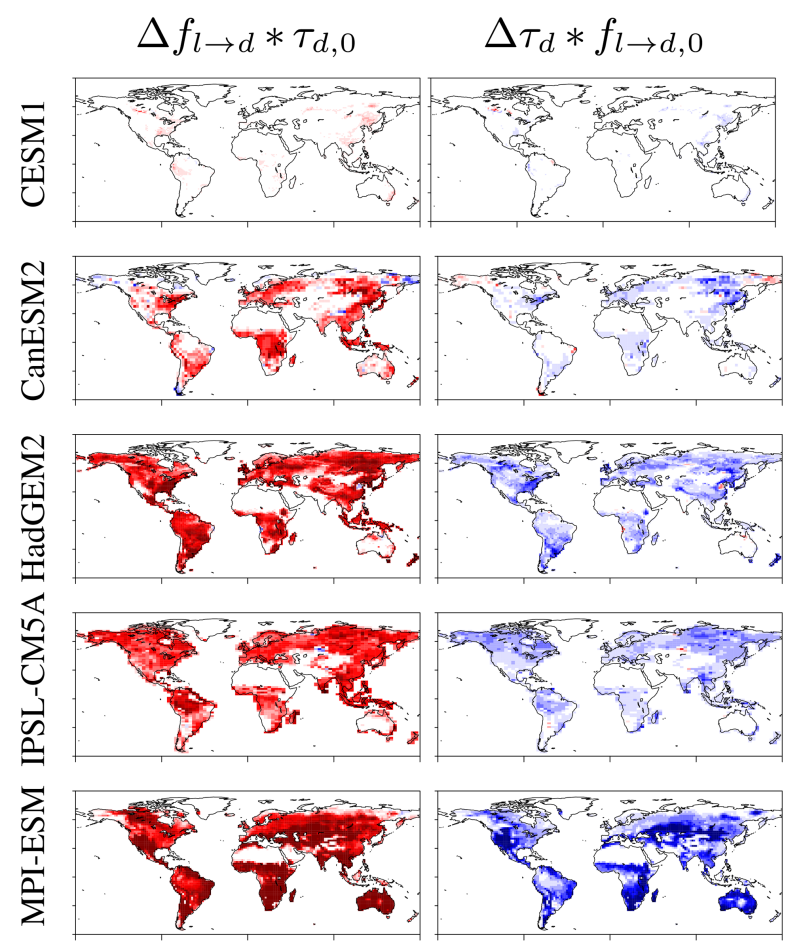

BGC-Coupled Dead Carbon Change $\left(\mathrm{kg} \mathrm{C} / \mathrm{m}^{2}\right)$

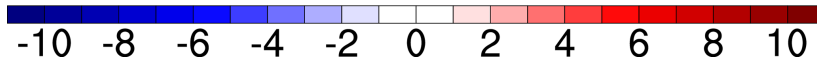

Figure 10. Responses of linearized equilibrium dead carbon pools ( $\mathrm{kg} \mathrm{C} \mathrm{m}^{-2}$ over the interval of $\mathrm{CO}_{2}$ doubling) in biogeochemically coupled (esmFixClim1) run. Left column shows productivity-driven changes to $\widehat{\mathrm{C}_{\mathrm{d}}}$. Right column shows turnover-driven changes to $\widehat{\mathrm{C}_{\mathrm{d}}}$.

SOM pools. Because the plant inputs contribute to the faster pools, which are able to equilibrate on the multi-decadal timescale of the changes considered here, while the slower pools are not able to equilibrate on this timescale, an additional input of carbon into these faster pools shifts the bulk $\tau_{\mathrm{d}}$ towards that of the faster pools. Another way of describing this is that flux-weighted turnover times are much faster than mass-weighted turnover times, and therefore, fluxes will equilibrate more rapidly than stocks will, over a given timeperiod, in response to a change in inputs. Thus, the anticorrelation between changing productivity and turnover is a result of the short-circuitedness (Rodhe, 2000) common to most biogeochemical systems. Given time to fully equilibrate, $\tau_{\mathrm{d}}$ should return to a value closer to its original value, though somewhat modified due to the changed environmental conditions. We note that, in soil decomposition studies, a change in turnover time driven by a change in inputs is frequently referred to as a priming mechanism, and the process by which such priming occurs is generally thought to be an increase in microbial activity in response to elevated inputs. In the set of models considered here, all decomposition is modeled as a first-order decay process with pool-specific turnover times functions of only the abiotic soil climate, and therefore no actual priming can occur. Therefore, we call this phenomenon of a transient reduction in turnover time in response to an increase in productivity "false priming", and note here that it explains the majority of the observed change in $\tau_{\mathrm{d}}$ in these fully coupled runs.

To graphically illustrate why false priming occurs, we use a toy box-model experiment to replicate the qualitative result from the ESMs (Fig. 12). Consider a simple three-pool system, with fixed pool turnover times $\left(\tau_{i}\right)$ of 1,10 , and 100 years, a sequential cascade (i.e., carbon flows from $f_{\mathrm{NPP}}$ $\rightarrow$ pool $1 \rightarrow$ pool $2 \rightarrow$ pool 3 ), and fixed carbon use efficiencies $\left(e_{i}\right.$; the fraction of carbon that is passed to the next pool rather than lost as heterotrophic respiration) of $0.3,0.3$, and 0.0 for pools 1,2 , and 3 , respectively; this gives a rough magnitude of the degree of short-circuitedness of the decomposition cascades in the ESMs. Mathematically, this simple system is described as:

$$
\begin{aligned}
& \frac{\mathrm{dC}_{1}}{\mathrm{~d} t}=f_{\mathrm{NPP}}-\frac{\mathrm{C}_{1}}{\tau_{1}} \\
& \frac{\mathrm{d} \mathrm{C}_{2}}{\mathrm{~d} t}=\frac{e_{1} \mathrm{C}_{1}}{\tau_{1}}-\frac{\mathrm{C}_{2}}{\tau_{2}} \\
& \frac{\mathrm{dC}}{\mathrm{d} t}=\frac{e_{2} \mathrm{C}_{2}}{\tau_{2}}-\frac{\mathrm{C}_{3}}{\tau_{3}} \\
& f_{\mathrm{Rh}}=\frac{\left(1-e_{1}\right) \mathrm{C}_{1}}{\tau_{1}}+\frac{\left(1-e_{2}\right) \mathrm{C}_{2}}{\tau_{2}}+\frac{\left(1-e_{3}\right) \mathrm{C}_{3}}{\tau_{3}} \\
& \mathrm{C}_{\mathrm{d}}=\mathrm{C}_{1}+\mathrm{C}_{2}+\mathrm{C}_{3} \\
& \tau_{1}=1, \tau_{2}=10, \tau_{3}=100, e_{1}=0.3, e_{2}=0.3, e_{3}=0 .
\end{aligned}
$$

If this system is equilibrated under a constant $f_{\mathrm{NPP}}$, then an exponentially increasing $f_{\mathrm{NPP}}$ (here at $0.3 \% \mathrm{yr}^{-1}$ ), results in $f_{\mathrm{Rh}}$ that increases almost as fast as $f_{\mathrm{NPP}}$, while $\mathrm{C}_{\mathrm{d}}$ responds more slowly. As a result, $\tau_{\mathrm{d}}$, because it is calculated as the ratio of $\frac{C_{d}}{f_{\mathrm{Rh}}}$, decreases in response to rising plant carbon inputs, as is seen in the CMIP5 ESMs. This response happens even when the specified turnover times of each individual pool do not change, and so the reduction in $\tau_{\mathrm{d}}$ can occur irrespective of environmental or microbial changes. Note that this reduction in $\tau$ is different from what would be expected if $\tau$ were calculated using inputs rather than outputs; in that case, $\tau$ would always drop in response to an increase in inputs, even for a well-mixed single-pool system. Whereas $\tau$ defined based on outputs, as we do here, would not change for a single-pool system in response to changing inputs, and only changes in Fig. 12 due to the multiple timescales of adjustment that characterize a multi-pool system.

For changes to $C_{d}$ in the radiatively coupled run, one would intuitively expect a loss of carbon due to reduced turnover times with warming, particularly at high latitudes where initial stocks are high. This is not what the models predict though (Fig. 11); instead, the models tend to lose $C_{d}$ in the tropics and are either neutral or gain $\mathrm{C}_{\mathrm{d}}$ at high latitudes. The loss in the tropics is mainly driven by reductions 


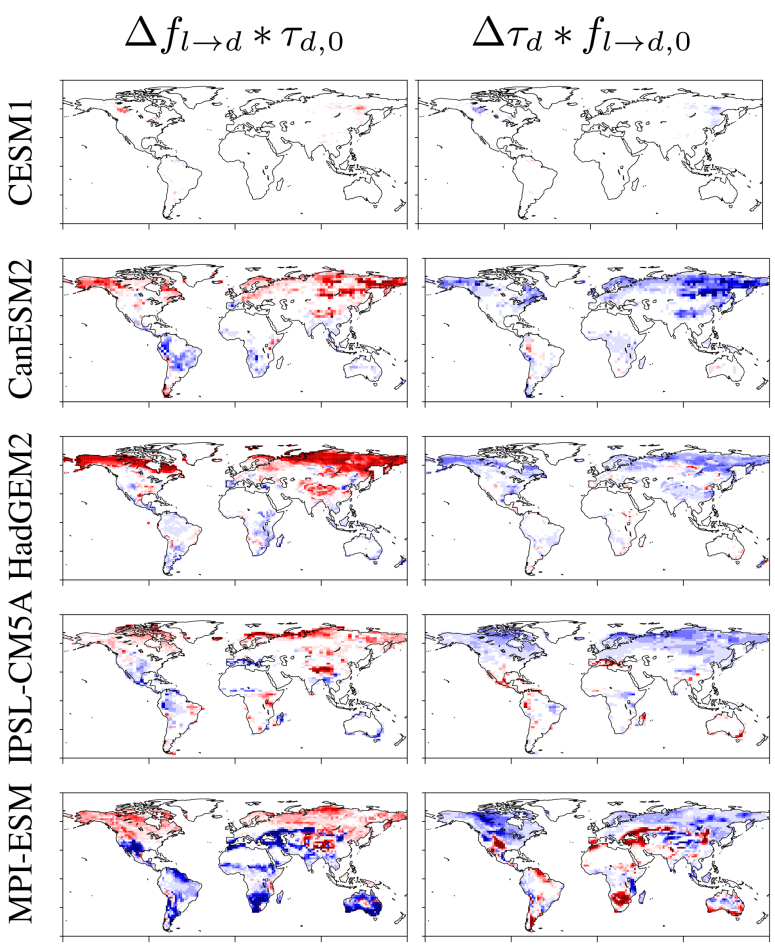

Rad.-Coupled Dead Carbon Change $\left(\mathrm{kg} \mathrm{C} / \mathrm{m}^{2}\right)$

$\begin{array}{lllllllllll}-10 & -8 & -6 & -4 & -2 & 0 & 2 & 4 & 6 & 8 & 10\end{array}$

Figure 11. Responses of linearized equilibrium dead carbon pools ( $\mathrm{kg} \mathrm{C} \mathrm{m}^{-2}$ over the interval of $\mathrm{CO}_{2}$ doubling) in radiatively coupled (esmFdbk1) run. Left column shows productivity-driven changes to $\widehat{\mathrm{C}_{\mathrm{d}}}$. Right column shows turnover-driven changes to $\widehat{\mathrm{C}_{\mathrm{d}}}$.

in $f_{1 \rightarrow \mathrm{d}}$, following reductions in $f_{\text {npp }}$ (Fig. 6), which are partially offset by compensating increases in $\tau_{\mathrm{d}}$ that again reflect the faster adjustment to changed $f_{1 \rightarrow \mathrm{d}}$ (in this case reduced) in fast rather than slow pools. The models that show increased $C_{d}$ at high latitudes appear to be driven by an increase in the $f_{1 \rightarrow \mathrm{d}}$ term. However, this is likely to be at least partially an artifact of the fact that these models do not include permafrost carbon processes, which limits the intrinsic sensitivity of $\tau_{\mathrm{d}}$ to warming and, therefore, the amount of carbon that they could lose under warming.

The fact that $\tau_{\mathrm{d}}$ in ESMs decreases under elevated $\mathrm{CO}_{2}$ has been shown before (e.g., Matthews et al., 2007), however the explanation for this behavior has been that it is due to a reduction in the limitation of decomposition by soil moisture as a result of $\mathrm{CO}_{2}$ fertilization. However, this explanation does not explain why this relationship is observed uniformly across ecosystems and models under $\mathrm{CO}_{2}$ fertilization (given the typically nonlinear form of moisture controls on respiration), nor why the response to turnover-driven carbon changes should be so highly correlated with changes in the soil carbon input term. The observation that the response under the fully coupled run is similar to that of the biogeo-

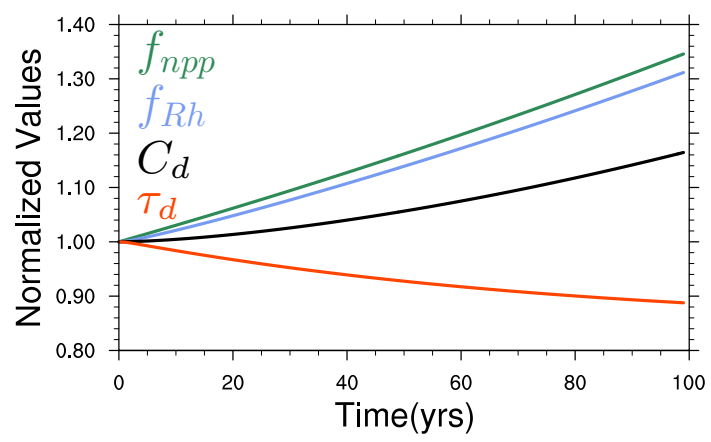

Figure 12. Box model experiment to illustrate the phenomenon of "false priming". Results are from a simplified system: three pools with fixed turnover times of 1,10 , and 100 years, arranged in a sequential cascade and fixed carbon use efficiency of $0.3,0.3$, and 0.0 (Eq. 16). Here, the system is perturbed from steady-state by an exponential NPP increase, $f_{\mathrm{NPP}}$, of $0.3 \% \mathrm{yr}^{-1}$. Because fluxweighted turnover in such a system is faster than mass-weighted turnover, $f_{\mathrm{Rh}}$ responds faster than $\mathrm{C}_{\mathrm{d}}$, and therefore aggregated $\tau_{\mathrm{d}}$ drops in response to increased inputs even though the carbon increases and the individual turnover times of each pool remain the same.

chemically coupled run requires a fundamental change in the interpretation of the model prediction of changing $\tau_{\mathrm{d}}$, from the interpretation that soil carbon tends to increase under climate change experiments despite a reduction in $\tau_{\mathrm{d}}$ (e.g., Todd-Brown et al., 2014), to an interpretation in which $\tau_{\mathrm{d}}$ tends to decrease under climate change mainly as a transient response to increasing productivity that leads to increasing soil carbon. While we do expect changes to the intrinsic $\tau_{\mathrm{d}}$ in the models, it is necessary to separate out what these changes would be in the presence of changing inputs.

In order to make this separation, we diagnose a falsepriming coefficient $\left(c_{\mathrm{fp}}\right)$ from the biogeochemically coupled experiment, which we define as the ratio of the turnoverdriven carbon changes to the productivity-driven carbon changes:

$$
\begin{aligned}
& \mathrm{c}_{\mathrm{fp}}=\left(\frac{\Delta \tau_{\mathrm{d}} f_{\mathrm{l} \rightarrow \mathrm{d}, 0}}{\Delta f_{\mathrm{l} \rightarrow \mathrm{d}} \tau_{\mathrm{d}, 0}}\right)_{\mathrm{BGC}} \\
& =\left(\frac{\Delta \tau_{\mathrm{d}} / \tau_{\mathrm{d}, 0}}{\Delta f_{\mathrm{l} \rightarrow \mathrm{d}} / f_{\mathrm{l} \rightarrow \mathrm{d}, 0}}\right)_{\mathrm{BGC}} .
\end{aligned}
$$

Multiplying $c_{\mathrm{fp}}$ by the productivity-driven dead carbon changes $\left(\Delta f_{1 \rightarrow \mathrm{d}} \tau_{\mathrm{d}, 0}\right)$ in the fully coupled and radiatively coupled experiments allows an estimate of the turnoverdriven changes to the dead carbon pools arising through the false-priming mechanism. This can then be subtracted from the total turnover-driven change to give the turnover-driven change in the absence of false priming, $\left(\Delta \tau_{\mathrm{d}} f_{\mathrm{l} \rightarrow \mathrm{d}, 0}\right)^{\prime}$, via the following relationship: 


$$
\begin{aligned}
& \left(\Delta \tau_{\mathrm{d}} f_{\mathrm{l} \rightarrow \mathrm{d}, 0}\right)_{\mathrm{Rad}}^{\prime}=\left(\Delta \tau_{\mathrm{d}} f_{\mathrm{l} \rightarrow \mathrm{d}, 0}\right)_{\mathrm{Rad}} \\
& -\mathrm{c}_{\mathrm{fp}}\left(\Delta f_{\mathrm{l} \rightarrow \mathrm{d}} \tau_{\mathrm{d}, 0}\right)_{\mathrm{Rad}} \\
& \left(\Delta \tau_{\mathrm{d}} f_{\mathrm{l} \rightarrow \mathrm{d}, 0}\right)_{\text {Full }}^{\prime}=\left(\Delta \tau_{\mathrm{d}} f_{\mathrm{l} \rightarrow \mathrm{d}, 0}\right)_{\text {Full }} \\
& -\mathrm{c}_{\mathrm{fp}}\left(\Delta f_{\mathrm{l} \rightarrow \mathrm{d}} \tau_{\mathrm{d}, 0}\right)_{\text {Full }} .
\end{aligned}
$$

The geographical patterns of $\left(\Delta \tau_{\mathrm{d}} f_{\mathrm{l} \rightarrow \mathrm{d}, 0}\right)_{\mathrm{Rad}}^{\prime}$ and $\left(\Delta \tau_{\mathrm{d}} f_{1 \rightarrow \mathrm{d}, 0}\right)_{\text {Full }}^{\prime}$ (Fig. 13) show an estimate of the turnoverdriven equilibrium dead carbon changes in response to climate change, in the absence of the false-priming effect. Since the climate changes are similar in the fully coupled and radiatively coupled cases, the spatial patterns in the two experiments are expected to be similar for each model. The observed similarity supports the validity of the approach, that subtracting the false priming response allows for a more unambiguous identification of the climate controls on turnover. The overall response corresponds more closely to the expected changes in dead carbon pools, with widespread - but smaller - losses due to warming-driven reductions in the turnover times.

False priming, the transient reduction in soil turnover times under $\mathrm{CO}_{2}$ fertilization, also has important implications for interpreting experimental $\mathrm{CO}_{2}$ manipulations. Heterotrophic respiration is often observed to increase more rapidly than the total amount of soil carbon under elevated $\mathrm{CO}_{2}$, which implies a reduction in $\tau_{\mathrm{d}}$ with $\mathrm{CO}_{2}$ enrichment, and this has been taken as evidence of priming processes (e.g., van Groenigen et al., 2014). Our results here show that this behavior is predicted by the CMIP5 ESMs, none of which include mechanisms for microbial priming. Therefore, such an observation on its own cannot be used to infer more complex dynamics such as priming (Georgiou et al., 2015). This response is in fact predicted by any multi-pool firstorder model (Fig. 12) in which the flux-weighted turnover is faster than the mass-weighted turnover, where heterotrophic respiration equilibrates faster than soil carbon to any perturbation.

This analysis points to the proposed mechanism of false priming to explain the observed anticorrelation between productivity-driven and turnover-driven changes to dead carbon pools in each of the models and experimental forcings used. However, because the CMIP5 protocol did not require the reporting of pool sizes and fluxes, it is not possible to unambiguously determine the changes to $\tau_{i}$ of individual pools as opposed to the bulk $\tau_{\mathrm{d}}$ of the full set of dead pools. Since the true equilibrium changes in $C_{d}$ are controlled by the intrinsic changes to $\tau_{i}$ for each of the pools separately, rather than the bulk $\tau_{\mathrm{d}}$ changes that are affected by changes to the distributions among the dead pools irrespective of changes to intrinsic decomposition rates, it would be useful to be able to separate out these effects. The $c_{\mathrm{fp}}$ separation described above provides one approach to doing this. Since most terrestrial carbon models distinguish between litter and SOM, we

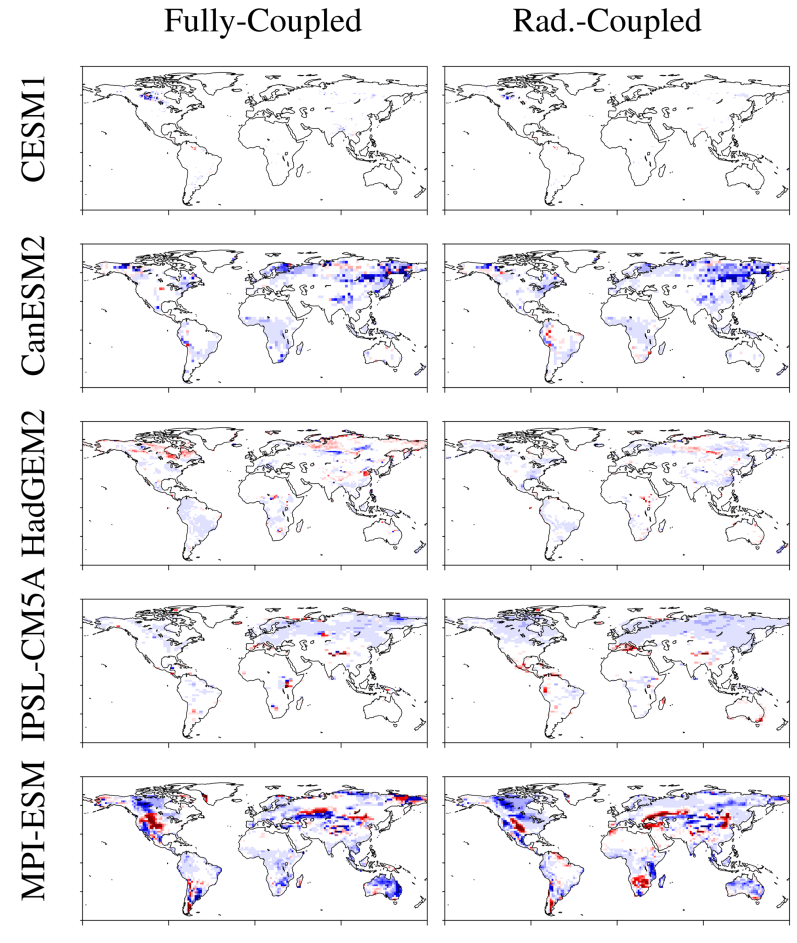

False-Priming Corrected Dead Carbon Change $\left(\mathrm{kg} \mathrm{C} / \mathrm{m}^{2}\right)$

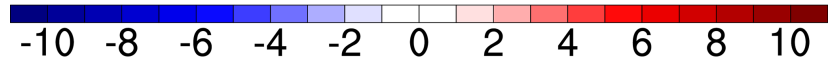

Figure 13. Maps of turnover-driven linearized equilibrium dead carbon changes after false priming effect has been removed, $\left(\Delta \tau_{\mathrm{d}} \times f_{1 \rightarrow \mathrm{d}, 0}\right)^{\prime}$, for the fully coupled (1pctCO2) and radiatively coupled (esmFdbk1) experiments. False priming is removed by regressing the change in input-driven dead carbon against the change in turnover-driven dead carbon within the biogeochemically coupled (esmFixClim1) experiment, and then for each of the other two experiments, using this value to calculate a total false priming effect and then subtracting it from the calculated turnover-driven equilibrium dead carbon change (Eq. 18).

propose at a minimum that future CMIP experiments separate out the $f_{\mathrm{Rh}}$ from fast-responding litter versus from slowresponding SOM, to better distinguish transient effects such as false priming from intrinsic changes to $\tau_{\mathrm{d}}$.

\subsection{Estimating the magnitude of inter-model uncertainty on different driving terms of carbon cycle feedbacks}

A critical step in reducing the uncertainty in model estimates of carbon cycle feedbacks is to identify which processes contribute most strongly to the spread in model estimates. One way of approaching this is to use the framework outlined above to separate ensemble-mean responses from individualmodel responses of the various terms in the equations presented. We calculate this inter-model uncertainty using eight main terms: the initial state and fractional changes to both 
the inputs and turnover times of both the live and dead pools. Listed out, these terms are: $f_{\mathrm{NPP}, 0}, \tau_{1,0}, \frac{\Delta f_{\mathrm{NPP}}}{f_{\mathrm{NPP}, 0}}, \frac{\Delta \tau_{1}}{\tau_{1,0}}, f_{1 \rightarrow \mathrm{d}, 0}$, $\tau_{\mathrm{d}, 0}, \frac{\Delta f_{\mathrm{l} \rightarrow \mathrm{d}}}{f_{\mathrm{l} \rightarrow \mathrm{d}, 0}}$, and $\frac{\Delta \tau_{\mathrm{d}}}{\tau_{\mathrm{d}, 0}}$. In addition, for the radiatively coupled and fully coupled experiments, we consider one final term, the fractional turnover-driven dead carbon change after subtracting the false priming effect, $\frac{\Delta \tau_{\mathrm{d}}{ }^{\prime}}{\tau_{\mathrm{d}, 0}}$, calculated as in Eq. (18). For each of these terms, we put all model estimates for each experiment on a common grid (using a conservative remapping), and calculate the total linearized equilibrium changes to the live and dead pools (Eqs. 13 and 14) using the inter-model ensemble-mean values of all other terms in the equation, and the individual-model values of only that term. For the uncertainty with respect to the initial conditions, we calculate and sum both the productivity-driven and turnoverdriven changes; for the inter-model uncertainty in the fractional changes, we calculate only the term corresponding to that change. In all cases, the spread in the estimates arises from inter-model uncertainty of just that term and is therefore an estimate of the uncertainty in the carbon response to only that term.

The results of this uncertainty disaggregation are shown in Fig. 14. For the live pools, the carbon response to intermodel uncertainty in $f_{\mathrm{NPP}, 0}$ is smaller than that due to intermodel uncertainty in $\tau_{1,0}$ for all three forcings, while the inter-model uncertainty in $\frac{\Delta f_{\mathrm{NPP}}}{f_{\mathrm{NPP}, 0}}$ is larger than that due to inter-model uncertainty in $\frac{\Delta \tau_{1}}{\tau_{1,0}}$ for all three forcings. The same pattern holds for the dead pools: the carbon response to inter-model uncertainty in $f_{1 \rightarrow \mathrm{d}, 0}$ is smaller than that due to inter-model uncertainty in $\tau_{\mathrm{d}, 0}$ for all three forcings, while the inter-model uncertainty in $\frac{\Delta f_{\mathrm{l} \rightarrow \mathrm{d}}}{f_{\mathrm{l} \rightarrow \mathrm{d}, 0}}$ is larger than that due to inter-model uncertainty in $\frac{\Delta \tau_{\mathrm{d}}}{\tau_{\mathrm{d}, 0}}$ for all three forcings. Much of the spread in the fully coupled turnover-driven dead carbon changes is driven by false priming, so removing that gives a narrow uncertainty that is more comparable between the fully coupled and radiatively coupled experiments.

The implications of these results are that the models agree reasonably well on their initial conditions of vegetation productivity and the fraction that makes it to dead pools. They agree less well on their initial conditions of turnover times (Carvalhais et al., 2014) for both the live and dead pools, and this uncertainty in initial turnover time drives much of the uncertainty in the carbon responses to global change. For the productivity and turnover responses to the global change forcings, however, the patterns are opposite: the models' agreement on the carbon response to the fractional change in turnover times, for both the live and dead pools, is higher than the models' agreement on fractional change in inputs.

The key question is whether the model agreement that changing turnover times are relatively less important than changing productivity is real or not. For dead pools, the models do not include key processes such as permafrost carbon dynamics, which are a potentially powerful turnover-driven carbon response to warming at high latitudes (Koven et al.,

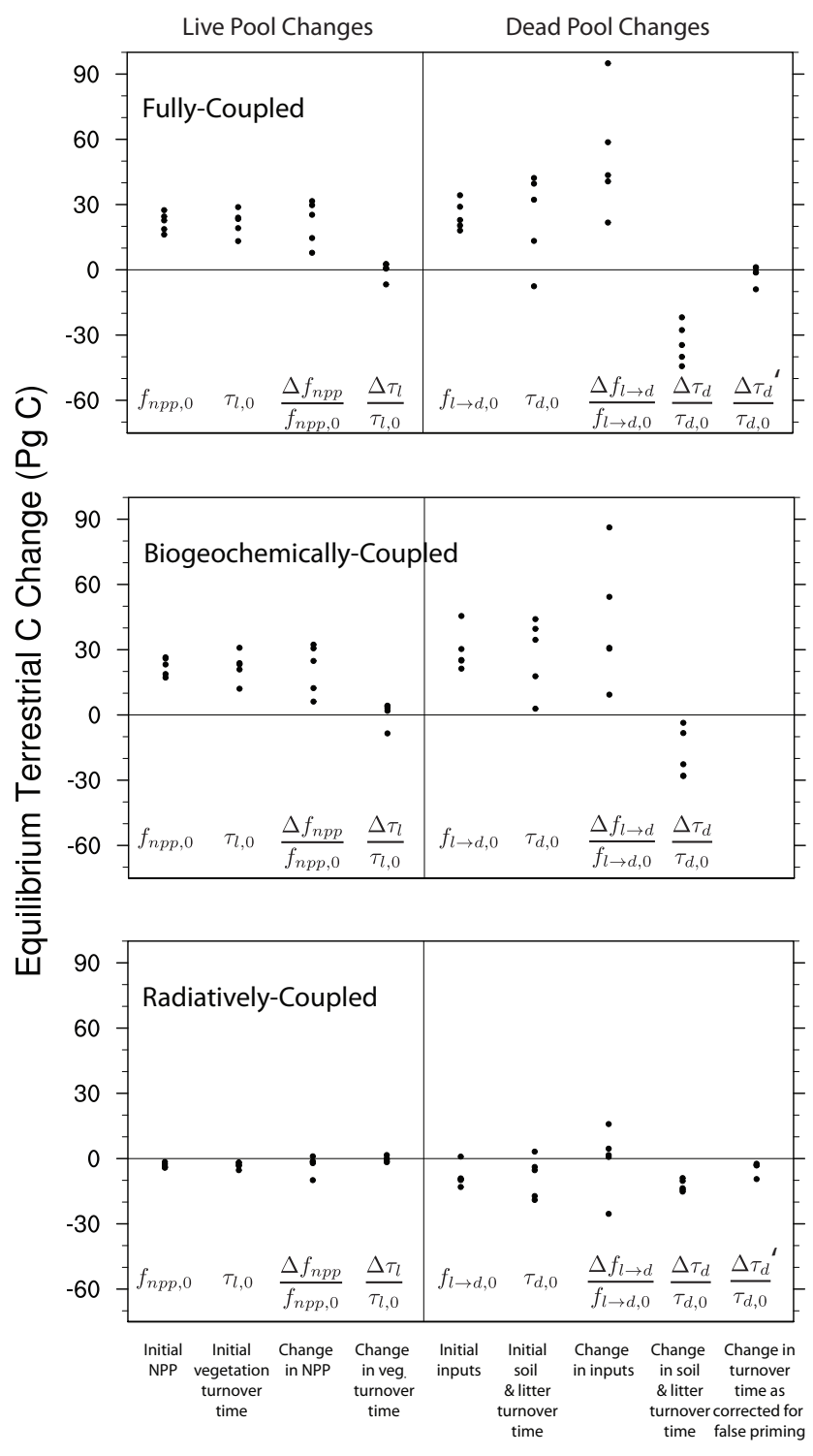

Figure 14. Inter-model uncertainty in total integrated linearized equilibrium carbon responses resulting from each of the driving terms. The left four columns are the terms that drive live carbon changes (from left to right): initial productivity, initial turnover times, fractional change in productivity, and fractional change in turnover times. The right four columns are the corresponding controls on dead carbon (from left to right): initial productivity, initial turnover times, fractional change in productivity, and fractional change in turnover times. For each term, the relevant linearized equilibrium carbon stock changes were calculated using the individual model values for that term, and multi-model ensemble-mean values for all of the other terms, so the model spread reflects the uncertainty in the response to just that term.

2011); they furthermore do not include the processes behind priming and SOM stabilization processes such as mineral surface control on carbon preservation (Wieder et al., 2013; Riley et al., 2014), which could also influence ac- 
tual carbon turnover times and their response to both climate change and $\mathrm{CO}_{2}$ fertilization (Schmidt et al., 2011). For the live pools, the model representation of mortality is generally static (Powell et al., 2013), and the representation of allocation is either static or, in the case of the dynamic schemes, poorly tested and highly uncertain, both in the mean state and in response to productivity changes (Malhi et al., 2011; De Kauwe et al., 2014). Furthermore, all of these models use the "big-wood" approximation (Wolf et al., 2011), i.e., that wood carbon can be represented as a homogeneous pool, which may intrinsically bias the results because it ignores the stand dynamics that govern mortality and therefore wood turnover in real forests. A conceptually similar analysis of carbon dynamics in a second-generation dynamic vegetation model that has more complex representation of vegetation distributions, allocation, and stand dynamics showed a larger role for vegetation dynamics, but still found that NPP responses governed the majority of carbon responses (Ahlström et al., 2015) to combined climate change and changing $\mathrm{CO}_{2}$. Because of these common biases, it is unclear if the carbon feedback uncertainty, as sampled through this set of models, accurately represents the actual uncertainty in the Earth system.

\section{Conclusions}

The method presented here, of separating the changes to equilibrium live and dead carbon storage by productivity versus turnover, provides insights into the relative magnitudes of different controls on ecosystem carbon storage response to global change. We show here that the transient responses of productivity and turnover are not independent. This is particularly the case for dead pools, where all five models show a strong and consistent anticorrelation between changes to productivity-driven and turnover-driven carbon under all three forcing scenarios, which we call "false priming". It may also be the case for live pools, where at least one model (HadGEM2) shows an anticorrelation between changes to productivity-driven and turnover-driven carbon; while another model (IPSL-CM5A) shows a weak positive correlation. The observation that changes to dead carbon residence times are not independent from changes to inputs into the decomposition cascade of the models underscores that complex behavior can emerge from relatively simple multipool exponential decay systems common to these models.

Assessing the uncertainty in the carbon responses due to inter-model spread in initial values of and fractional changes to productivity and turnover shows that more of the initialcondition uncertainty arises from differing model estimates of turnover than productivity, whereas uncertainty in the carbon responses to changing productivity versus turnover is dominated more by productivity. The first of these relationships is supported by studies of other model intercomparison analyses (e.g., Friend et al., 2014), while the latter may be an artifact of a common lack of representation of the mechanisms behind changing turnover. Thus, while understanding the responses of productivity to changing climate and $\mathrm{CO}_{2}$ is clearly important, it is also important to understand that turnover times of both live and dead carbon pools arise as emergent responses to complex ecosystem interactions. It is therefore critical to more accurately represent the processes that control turnover times under the historical environment, and may lead to changing turnover times in response to environmental change, in the next generation of ESMs.

Acknowledgements. This research was supported by the Director, Office of Science, Office of Biological and Environmental Research of the U.S. Department of Energy under Contract no. DE-AC02-05CH11231 as part of their Regional and Global Climate Modeling Program. We acknowledge the World Climate Research Programme's Working Group on Coupled Modelling, which is responsible for CMIP, and we thank the climate modeling groups listed in Table 1 for producing and making available their model output. For CMIP the U.S. Department of Energy's Program for Climate Model Diagnosis and Intercomparison provides coordinating support and led development of software infrastructure in partnership with the Global Organization for Earth System Science Portals. CDJ was supported by the Joint UK DECC/Defra Met Office Hadley Centre Climate Programme (GA01101). We thank Peter Cox for helpful discussion on TRIFFID dynamics. We thank Inez Fung, Jim Randerson, Margaret Torn, and Yiqi Luo for helpful discussions. We thank Yujie $\mathrm{He}$ and an anonymous referee for reviews that improved the manuscript.

Edited by: K. Thonicke

\section{References}

Ahlström, A., Xia, J., Arneth, A., Luo, Y., and Smith, B.: Importance of vegetation dynamics for future terrestrial carbon cycling, Environ. Res. Lett., 10, 054019, doi:10.1088/17489326/10/5/054019, 2015.

Anav, A., Murray-Tortarolo, G., Friedlingstein, P., Sitch, S., Piao, S., and Zhu, Z.: Evaluation of Land Surface Models in Reproducing Satellite Derived Leaf Area Index over the High-Latitude Northern Hemisphere. Part II: Earth System Models, Remote Sens., 5, 3637-3661, doi:10.3390/rs5083637, 2013.

Arora, V. K., Scinocca, J. F., Boer, G. J., Christian, J. R., Denman, K. L., Flato, G. M., Kharin, V. V., Lee, W. G., and Merryfield, W. J.: Carbon emission limits required to satisfy future representative concentration pathways of greenhouse gases, Geophys. Res. Lett., 38, L05805, doi:10.1029/2010GL046270, 2011.

Arora, V. K., Boer, G. J., Friedlingstein, P., Eby, M., Jones, C. D., Christian, J. R., Bonan, G., Bopp, L., Brovkin, V., Cadule, P., Hajima, T., Ilyina, T., Lindsay, K., Tjiputra, J. F., and $\mathrm{Wu}, \mathrm{T}$.: Carbon-concentration and carbon-climate feedbacks in CMIP5 Earth system models, J. Climate, 26, 5289-5314, doi:10.1175/JCLI-D-12-00494.1, 2013.

Brienen, R. J. W., Phillips, O. L., Feldpausch, T. R., Gloor, E., Baker, T. R., Lloyd, J., Lopez-Gonzalez, G., MonteagudoMendoza, A., Malhi, Y., Lewis, S. L., Vasquez Martinez, R., 
Alexiades, M., Alvarez Davila, E., Alvarez-Loayza, P., Andrade, A., Aragao, L. E. O. C., Araujo-Murakami, A., Arets, E. J. M. M., Arroyo, L., Aymard C., G. A., Banki, O. S., Baraloto, C., Barroso, J., Bonal, D., Boot, R. G. A., Camargo, J. L. C., Castilho, C. V., Chama, V., Chao, K. J., Chave, J., Comiskey, J. A., Cornejo Valverde, F., da Costa, L., de Oliveira, E. A., Di Fiore, A., Erwin, T. L., Fauset, S., Forsthofer, M., Galbraith, D. R., Grahame, E. S., Groot, N., Herault, B., Higuchi, N., Honorio Coronado, E. N., Keeling, H., Killeen, T. J., Laurance, W. F., Laurance, S., Licona, J., Magnussen, W. E., Marimon, B. S., Marimon-Junior, B. H., Mendoza, C., Neill, D. A., Nogueira, E. M., Nunez, P., Pallqui Camacho, N. C., Parada, A., PardoMolina, G., Peacock, J., Pena-Claros, M., Pickavance, G. C., Pitman, N. C. A., Poorter, L., Prieto, A., Quesada, C. A., Ramirez, F., Ramirez-Angulo, H., Restrepo, Z., Roopsind, A., Rudas, A., Salomao, R. P., Schwarz, M., Silva, N., Silva-Espejo, J. E., Silveira, M., Stropp, J., Talbot, J., ter Steege, H., Teran-Aguilar, J., Terborgh, J., Thomas-Caesar, R., Toledo, M., Torello-Raventos, M., Umetsu, R. K., van der Heijden, G. M. F., van der Hout, P., Guimaraes Vieira, I. C., Vieira, S. A., Vilanova, E., Vos, V. A., and Zagt, R. J.: Long-term decline of the Amazon carbon sink, Nature, 519, 344-348, doi:10.1038/nature14283, 2015.

Brovkin, V., Raddatz, T., Reick, C. H., Claussen, M., and Gayler, V.: Global biogeophysical interactions between forest and climate, Geophys. Res. Lett., 36, L07405, doi:10.1029/2009GL037543, 2009.

Carvalhais, N., Forkel, M., Khomik, M., Bellarby, J., Jung, M., Migliavacca, M., Mu, M., Saatchi, S., Santoro, M., Thurner, M., Weber, U., Ahrens, B., Beer, C., Cescatti, A., Randerson, J. T., and Reichstein, M.: Global covariation of carbon turnover times with climate in terrestrial ecosystems, Nature, 514, 213-217, doi:10.1038/nature13731, 2014.

Ciais, P., Sabine, C., Bala, G., Bopp, L., Brovkin, V., Canadell, J., Chhabra, A., DeFries, R., Galloway, J., Heimann, M., Jones, C., Quéré, C. L., Myneni, R., Piao, S., and Thornton, P.: Climate Change 2013: The Physical Science Basis. Contribution of Working Group I to the Fifth Assessment Report of the Intergovernmental Panel on Climate Change, chap. Carbon and Other Biogeochemical Cycles, Cambridge University Press, 465-570, 2013.

Cox, P.: Description of the TRIFFID dynamic global vegetation model, Hadley Centre Technical Note 24, Met Office Hadley Centre, 16 pp., 2001.

Cramer, W., Bondeau, A., Woodward, F., Prentice, I., Betts, R., Brovkin, V., Cox, P., Fisher, V., Foley, J., Friend, A., Kucharik, C., Lomas, M., Ramankutty, N., Sitch, S., Smith, B., White, A., and Young-Molling, C.: Global response of terrestrial ecosystem structure and function to $\mathrm{CO}_{2}$ and climate change: results from six dynamic global vegetation models, Glob. Change Biol., 7, 357-373, 2001.

De Kauwe, M. G., Medlyn, B. E., Zaehle, S., Walker, A. P., Dietze, M. C., Wang, Y.-P., Luo, Y., Jain, A. K., El-Masri, B., Hickler, T., Wårlind, D., Weng, E., Parton, W. J., Thornton, P. E., Wang, S., Prentice, I. C., Asao, S., Smith, B., McCarthy, H. R., Iversen, C. M., Hanson, P. J., Warren, J. M., Oren, R., and Norby, R. J.: Where does the carbon go? A model-data intercomparison of vegetation carbon allocation and turnover processes at two temperate forest free-air $\mathrm{CO}_{2}$ enrichment sites, New Phytol., 203, 883-899, doi:10.1111/nph.12847, 2014.
Delbart, N., Ciais, P., Chave, J., Viovy, N., Malhi, Y., and Le Toan, T.: Mortality as a key driver of the spatial distribution of aboveground biomass in Amazonian forest: results from a dynamic vegetation model, Biogeosciences, 7, 3027-3039, doi:10.5194/bg-7-3027-2010, 2010.

Friedlingstein, P., Joel, G., Field, C., and Fung, I.: Toward an allocation scheme for global terrestrial carbon models, Glob. Change Biol., 5, 755-770, 1999.

Friedlingstein, P., Cox, P., Betts, R., Bopp, L., von Bloh, W., Brovkin, V., Cadule, P., Doney, S., Eby, M., Fung, I., Bala, G., John, J., Jones, C., Joos, F., Kato, T., Kawamiya, M., Knorr, W., Lindsay, K., Matthews, H. D., Raddatz, T., Rayner, P., Reick, C., Roeckner, E., Schnitzler, K. G., Schnur, R., Strassmann, K., Weaver, A. J., Yoshikawa, C., and Zeng, N.: Climate-Carbon Cycle Feedback Analysis: Results from the C4MIP Model Intercomparison, J. Climate, 19, 3337-3353, 2006.

Friedlingstein, P., Meinshausen, M., Arora, V. K., Jones, C. D., Anav, A., Liddicoat, S. K., and Knutti, R.: Uncertainties in CMIP5 climate projections due to carbon cycle feedbacks, J. Climate, 27, 511-526, doi:10.1175/JCLI-D-12-00579.1, 2013.

Friend, A. D., Lucht, W., Rademacher, T. T., Keribin, R., Betts, R., Cadule, P., Ciais, P., Clark, D. B., Dankers, R., Falloon, P. D., Ito, A., Kahana, R., Kleidon, A., Lomas, M. R., Nishina, K., Ostberg, S., Pavlick, R., Peylin, P., Schaphoff, S., Vuichard, N., Warszawski, L., Wiltshire, A., and Woodward, F. I.: Carbon residence time dominates uncertainty in terrestrial vegetation responses to future climate and atmospheric $\mathrm{CO}_{2}$, P. Natl. Acad. Sci., 111, 3280-3285, doi:10.1073/pnas.1222477110, 2014.

Fung, I., Doney, S., Lindsay, K., and John, J.: Evolution of carbon sinks in a changing climate, P. Natl. Acad. Sci. USA, 102, 11201-11206, doi:10.1073/pnas.0504949102, 2005.

Georgiou, K., Koven, C. D., Riley, W. J., and Torn, M. S.: Toward improved model structures for analyzing priming: potential pitfalls of using bulk turnover times, Glob. Change Biol., doi:10.1111/gcb.13039, in press, 2015.

Gregory, J. M., Jones, C. D., Cadule, P., and Friedlingstein, P.: Quantifying Carbon Cycle Feedbacks, J. Climate, 22, 52325250, doi:10.1175/2009JCLI2949.1, 2009.

Hoffman, F. M., Randerson, J. T., Arora, V. K., Bao, Q., Cadule, P., Ji, D., Jones, C. D., Kawamiya, M., Khatiwala, S., Lindsay, K., et al.: Causes and implications of persistent atmospheric carbon dioxide biases in Earth System Models, J. Geophys. Res.Biogeo., 119, 141-162, doi:10.1002/2013JG002381, 2014.

Jones, C., Cox, P., and Huntingford, C.: Uncertainty in climatecarbon-cycle projections associated with the sensitivity of soil respiration to temperature, Tellus B, 55, 642-648, 2003.

Jones, C. D., Hughes, J. K., Bellouin, N., Hardiman, S. C., Jones, G. S., Knight, J., Liddicoat, S., O’Connor, F. M., Andres, R. J., Bell, C., Boo, K.-O., Bozzo, A., Butchart, N., Cadule, P., Corbin, K. D., Doutriaux-Boucher, M., Friedlingstein, P., Gornall, J., Gray, L., Halloran, P. R., Hurtt, G., Ingram, W. J., Lamarque, J.-F., Law, R. M., Meinshausen, M., Osprey, S., Palin, E. J., Parsons Chini, L., Raddatz, T., Sanderson, M. G., Sellar, A. A., Schurer, A., Valdes, P., Wood, N., Woodward, S., Yoshioka, M., and Zerroukat, M.: The HadGEM2-ES implementation of CMIP5 centennial simulations, Geosci. Model Dev., 4, 543-570, doi:10.5194/gmd-4-543-2011, 2011. 
Keeling, H. C. and Phillips, O. L.: The global relationship between forest productivity and biomass, Glob. Ecol. Biogeogr., 16, 618631, doi:10.1111/j.1466-8238.2007.00314.x, 2007.

Koven, C. D., Ringeval, B., Friedlingstein, P., Ciais, P., Cadule, P., Khvorostyanov, D., Krinner, G., and Tarnocai, C.: Permafrost carbon-climate feedbacks accelerate global warming, P. Natl. Acad. Sci., 108, 14769-14774, doi:10.1073/pnas.1103910108, 2011.

Krinner, G., Viovy, N., de Noblet-Ducoudre, N., Ogee, J., Polcher, J., Friedlingstein, P., Ciais, P., Sitch, S., and Prentice, I.: A dynamic global vegetation model for studies of the coupled atmosphere-biosphere system, Global Biogeochem. Cy., 19, GB1015, doi:10.1029/2003GB002199, 2005.

Malhi, Y.: The productivity, metabolism and carbon cycle of tropical forest vegetation, J. Ecol., 100, 65-75, doi:10.1111/j.13652745.2011.01916.x, 2012.

Malhi, Y., Baker, T., Phillips, O., Almeida, S., Alvarez, E., Arroyo, L., Chave, J., Czimczik, C., Di Fiore, A., Higuchi, N., Killeen, T., Laurance, S., Laurance, W., Lewis, S., Montoya, L., Monteagudo, A., Neill, D., Vargas, P., Patino, S., Pitman, N., Quesada, C., Salomao, R., Silva, J., Lezama, A., Martinez, R., Terborgh, J., Vinceti, B., and Lloyd, J.: The above-ground coarse wood productivity of 104 Neotropical forest plots, Glob. Change Biol., 10, 563-591, doi:10.1111/j.1529-8817.2003.00778.x, 2004.

Malhi, Y., Doughty, C., and Galbraith, D.: The allocation of ecosystem net primary productivity in tropical forests, Philos. T. R. Soc. B, 366, 3225-3245, doi:10.1098/rstb.2011.0062, 2011.

Matthews, H. D., Eby, M., Weaver, A. J., and Hawkins, B. J.: Primary productivity control of simulated carbon cycle-climate feedbacks, Geophys. Res. Lett., 32, L14708, doi:10.1029/2005GL022941, 2005.

Matthews, H. D., Eby, M., Ewen, T., Friedlingstein, P., and Hawkins, B. J.: What determines the magnitude of carbon cycle-climate feedbacks?, Global Biogeochem. Cy., 21, GB2012, doi:10.1029/2006GB002733, 2007.

Negrón-Juárez, R. I., Koven, C. D., Riley, W. J., Knox, R. G., and Chambers, J. Q.: Observed allocations of productivity and biomass, and turnover times in tropical forests are not accurately represented in CMIP5 Earth system models, Environ. Res. Lett., 10, 064017, doi:10.1088/1748-9326/10/6/064017, 2015.

Norby, R. J., DeLucia, E. H., Gielen, B., Calfapietra, C., Giardina, C. P., King, J. S., Ledford, J., McCarthy, H. R., Moore, D. J. P., Ceulemans, R., De Angelis, P., Finzi, A. C., Karnosky, D. F., Kubiske, M. E., Lukac, M., Pregitzer, K. S., Scarascia-Mugnozza, G. E., Schlesinger, W. H., and Oren, R.: Forest response to elevated $\mathrm{CO}_{2}$ is conserved across a broad range of productivity, $\mathrm{P}$. Natl. Acad. Sci. USA, 102, 18052-18056, 2005.

Norby, R. J., Warren, J. M., Iversen, C. M., Medlyn, B. E., and McMurtrie, R. E.: $\mathrm{CO}_{2}$ enhancement of forest productivity constrained by limited nitrogen availability, P. Natl. Acad. Sci., 107, 19368-19373, 2010.

Oleson, K. W., Lawrence, D. M., Bonan, G. B., Flanner, M. G., Kluzek, E., Lawrence, P. J., Levis, S., Swenson, S. C., Dai, P. E. T. A., Decker, M., Dickinson, R., Feddema, J., Heald, C. L., Hoffman, F., Lamarque, J.-F., Mahowald, N., Niu, G.-Y., Qian, T., Randerson, J., Running, S., Sakaguchi, K., Slater, A., Stöckli, R., Wang, A., Yang, Z.-L., Zeng, X., and Zeng, X.: Technical Description of version 4.0 of the Community Land Model (CLM), ncar technical note ncar/tn-478+str, national center for atmospheric research, P. O. Box 3000 BOULDER, COLORADO 80307-3000, 420 pp., 2010.

Powell, T. L., Galbraith, D. R., Christoffersen, B. O., Harper, A., Imbuzeiro, H. M. A., Rowland, L., Almeida, S., Brando, P. M., da Costa, A. C. L., Costa, M. H., Levine, N. M., Malhi, Y., Saleska, S. R., Sotta, E., Williams, M., Meir, P., and Moorcroft, P. R.: Confronting model predictions of carbon fluxes with measurements of Amazon forests subjected to experimental drought, New Phytol., 200, 350-365, doi:10.1111/nph.12390, 2013.

Raddatz, T. J., Reick, C. H., Knorr, W., Kattge, J., Roeckner, E., Schnur, R., Schnitzler, K.-G., Wetzel, P., and Jungclaus, J.: Will the tropical land biosphere dominate the climate-carbon cycle feedback during the twenty-first century?, Clim. Dynam., 29, 565-574, doi:10.1007/s00382-007-0247-8, 2007.

Reick, C. H., Raddatz, T., Brovkin, V., and Gayler, V.: Representation of natural and anthropogenic land cover change in MPI-ESM, J. Adv. Model. Earth Sys., 5, 459-482, doi:10.1002/jame.20022, 2013.

Riley, W. J., Maggi, F., Kleber, M., Torn, M. S., Tang, J. Y., Dwivedi, D., and Guerry, N.: Long residence times of rapidly decomposable soil organic matter: application of a multi-phase, multi-component, and vertically resolved model (BAMS1) to soil carbon dynamics, Geosci. Model Dev., 7, 1335-1355, doi:10.5194/gmd-7-1335-2014, 2014.

Rodhe, H.: Earth System Science, vol. 72 of International Geophysics Series, chap. Modeling biogeochemical cycles, 62-84, Academic Press, 2000.

Schmidt, M. W. I., Torn, M. S., Abiven, S., Dittmar, T., Guggenberger, G., Janssens, I. A., Kleber, M., Kogel-Knabner, I., Lehmann, J., Manning, D. A. C., Nannipieri, P., Rasse, D. P., Weiner, S., and Trumbore, S. E.: Persistence of soil organic matter as an ecosystem property, Nature, 478, 49-56, doi:10.1038/nature10386, 2011.

Sitch, S., Huntingford, C., Gedney, N., Levy, P. E., Lomas, M., Piao, S. L., Betts, R., Ciais, P., Cox, P., Friedlingstein, P., Jones, C. D., Prentice, I. C., and Woodward, F. I.: Evaluation of the terrestrial carbon cycle, future plant geography and climate-carbon cycle feedbacks using five Dynamic Global Vegetation Models (DGVMs), Glob. Change Biol., 14, 2015-2039, doi:10.1111/j.1365-2486.2008.01626.x, 2008.

Six, J., Conant, R., Paul, E., and Paustian, K.: Stabilization mechanisms of soil organic matter: Implications for C-saturation of soils, Plant Soil, 241, 155-176, 2002.

Stephenson, N. L., van Mantgem, P. J., Bunn, A. G., Bruner, H., Harmon, M. E., O'Connell, K. B., Urban, D. L., and Franklin, J. F.: Causes and implications of the correlation between forest productivity and tree mortality rates, Ecol. Monogr., 81, 527555, doi:10.1890/10-1077.1, 2011.

Taylor, J. A. and Lloyd, J.: Sources and sinks of atmospheric $\mathrm{CO}_{2}$, Australian J. Bot., 40, 407-418, 1992.

Taylor, K., Stouffer, R., and Meehl, G.: An overview of CMIP5 and the experiment design, B. Am. Meteorol. Soc., 93, 485-498, doi:10.1175/BAMS-D-11-00094.1, 2012.

Thornton, P. E., Lamarque, J.-F., Rosenbloom, N. A., and Mahowald, N. M.: Influence of carbon-nitrogen cycle coupling on land model response to $\mathrm{CO}_{2}$ fertilization and climate variability, Global Biogeochem. Cycles, 21, GB4018, doi:10.1029/2006GB002868, 2007. 
Todd-Brown, K. E. O., Randerson, J. T., Post, W. M., Hoffman, F. M., Tarnocai, C., Schuur, E. A. G., and Allison, S. D.: Causes of variation in soil carbon simulations from CMIP5 Earth system models and comparison with observations, Biogeosciences, 10, 1717-1736, doi:10.5194/bg-10-1717-2013, 2013.

Todd-Brown, K. E. O., Randerson, J. T., Hopkins, F., Arora, V., Hajima, T., Jones, C., Shevliakova, E., Tjiputra, J., Volodin, E., Wu, T., Zhang, Q., and Allison, S. D.: Changes in soil organic carbon storage predicted by Earth system models during the 21st century, Biogeosciences, 11, 2341-2356, doi:10.5194/bg-11-23412014, 2014.

van Groenigen, K. J., Qi, X., Osenberg, C. W., Luo, Y., and Hungate, B. A.: Faster Decomposition Under Increased Atmospheric $\mathrm{CO}_{2}$ Limits Soil Carbon Storage, Science, 344, 508-509, doi:10.1126/science.1249534, 2014.

Wieder, W. R., Bonan, G. B., and Allison, S. D.: Global soil carbon projections are improved by modelling microbial processes, Nature Clim. Change, 3, 909-912, doi:10.1038/nclimate1951, 2013.
Wieder, W. R., Boehnert, J., and Bonan, G. B.: Evaluating soil biogeochemistry parameterizations in Earth system models with observations, Global Biogeochem. Cy., 28, GB004665, doi:10.1002/2013GB004665, 2014.

Wolf, A., Ciais, P., Bellassen, V., Delbart, N., Field, C. B., and Berry, J. A.: Forest biomass allometry in global land surface models, Global Biogeochem. Cy., 25, GB3015, doi:10.1029/2010GB003917, 2011.

Xia, J., Luo, Y., Wang, Y.-P., and Hararuk, O.: Traceable components of terrestrial carbon storage capacity in biogeochemical models, Glob. Change Biol., 19, 2104-2116, doi:10.1111/gcb.12172, 2013.

Zhang, Q., Wang, Y. P., Matear, R. J., Pitman, A. J., and Dai, Y. J.: Nitrogen and phosphorous limitations significantly reduce future allowable $\mathrm{CO}_{2}$ emissions, Geophys. Res. Lett., 41, 632-637, doi:10.1002/2013GL058352, 2013. 